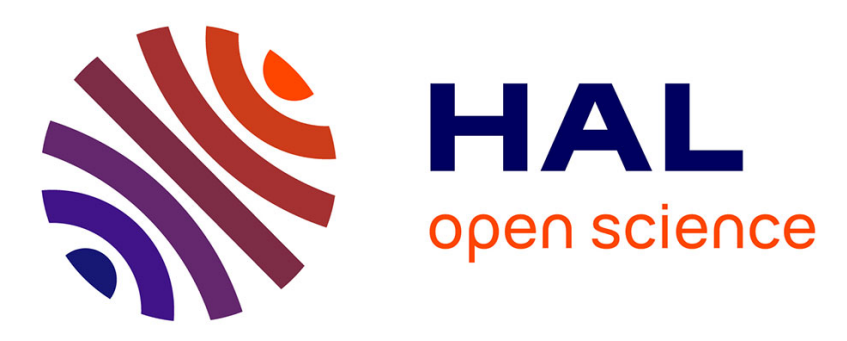

\title{
The reinforcement axiom under sequential positional rules
}

Sebastien Courtin, Boniface Mbih, Issofa Moyouwou, Thomas Senné

\section{To cite this version:}

Sebastien Courtin, Boniface Mbih, Issofa Moyouwou, Thomas Senné. The reinforcement axiom under sequential positional rules. Social Choice and Welfare, 2010, 35 (3), pp.473-500. 10.1007/s00355-0100449-6 . hal-00914864

\section{HAL Id: hal-00914864 \\ https://hal.science/hal-00914864}

Submitted on 9 Dec 2013

HAL is a multi-disciplinary open access archive for the deposit and dissemination of scientific research documents, whether they are published or not. The documents may come from teaching and research institutions in France or abroad, or from public or private research centers.
L'archive ouverte pluridisciplinaire HAL, est destinée au dépôt et à la diffusion de documents scientifiques de niveau recherche, publiés ou non, émanant des établissements d'enseignement et de recherche français ou étrangers, des laboratoires publics ou privés. 


\title{
The reinforcement axiom under sequential positional rules
}

\author{
Sébastien Courtin ${ }^{1}$, Boniface Mbih ${ }^{1}$, Issofa Moyouwou ${ }^{2}$, Thomas \\ Senné ${ }^{1}$ \\ 1 CREM UMR CNRS 6211, Faculté de Sciences Economiques et de Gestion, Uni- \\ versité de Caen, 14032 Caen, France. \\ 2 Ecole Normale Supérieure, B.P. 47, Yaoundé, Cameroun.
}

The date of receipt and acceptance will be inserted by the editor

\begin{abstract}
The reinforcement axiom roughly states that when an alternative is selected by two different constituencies, it must also be selected by their union. Hare and Coombs rules are special cases of sequential positional voting rules which are known to violate this axiom. In this paper, we first show that reinforcement can be violated by all such rules. We then evaluate, by the use of Monte Carlo simulations and the Fishburn-Gehrlein technique, the proportion of profiles at which this phenomenon occurs.
\end{abstract}

\section{Introduction}

In the theoretical debate on the attractiveness of Condorcet consistent social choice methods on the one hand, and positional (or scoring) systems - voting à la Borda - on the other hand, the two strongest arguments in favor of the second type of mechanisms are the participation axiom and the Young's reinforcement axiom (YRA). Roughly, according to the participation axiom, no voter can take advantage of not taking part to the election. For more details, see Nurmi (2005) or Mbih, Moyouwou and Zhao (2006) among others. In this contribution, we are only interested in $Y R A$.

The notion of reinforcement was first introduced by Smith (1973), under the name of separability. The intuition is as follows: if two different blocks of individuals rank an alternative at least as high as some other alternative, then so does the combination of the blocks with regard to these two alternatives.

Send offprint requests to: Offprints Assistant

Correspondence to: Boniface Mbih, Faculté de Sciences Economiques et de Gestion, Université de Caen, 14032 Caen Cedex. e-mail: boniface.mbih@unicaen.fr 
In the same way - and indeed at the same period - Young $(1974,1975)$ proposes a variant of the notion of separability, which he calls consistency. Following this idea, if two disjoint groups of individuals separately select two non-disjoint subsets of alternatives, then the union of these groups should exactly select the intersection of the two subsets. In fact, the difference between the two contributions lies in the type of social choice mechanisms studied: Young is concerned with social choice correspondences (selecting possibly more than a single alternative), while Smith is interested in aggregation functions (selecting a social ranking of alternatives from preferences reported by individual voters).

And finally, in the special context of social choice functions (correspondences selecting a unique outcome), Moulin (1988) introduces the phrase Young's reinforcement axiom.

Actual situations where this phenomenon could have arisen can also be found. In France, President Georges Pompidou and more recently President Jacques Chirac both abandoned the idea of submitting to the vote of the Congrès de Versailles, the bills on the reduction of the president's term of office from seven to five years in 1973 and the status of French Polynesia 1999, respectively, although those bills had been voted in both Assemblée Nationale and Sénat.

In the Condorcet-Borda debate, arguments in favor of positional rules $(P R)$, based on the notion of reinforcement, are summarized in Young's theorem (1975). This theorem shows that all $P R$ satisfy $Y R A$ whereas there is no Condorcet consistent social choice procedure satisfying $Y R A$.

There is no doubt about the importance of this result. However it does not take into consideration the potentially sequential aspects of positional rules. This paper is specifically concerned with sequential positional rules (see Definition 6), whose famous examples are the well-known Hare and Coombs methods.

Our goal is to examine precise conditions at which violations of Young's reinforcement axiom are susceptible to arise under sequential positional rules. Our main contribution in this context states that all sequential positional rules violate this axiom. This normative contribution is completed by a measure of the quantitative significance of the violation of $Y R A$.

The remainder of this paper is organized as follows: Section 2 is a presentation of the general framework with definitions, assumptions and some examples. Section 3 provides some general results on the behavior of sequential positional rules vis-à-vis the reinforcement axiom. Then, Section 4 studies the precise conditions at which a profile may violate the axiom, and frequencies are given in Section 5; finally, Section 6 discusses and concludes the paper.

\section{Notations and definitions}

Consider a finite set $N$ of $n$ individuals or voters, with $n \geq 2$ and a finite set $A$ of $m$ alternatives. And suppose two disjoint groups (or constituencies) 
$T_{1}$ and $T_{2}$ of individuals, and $T_{1} \cup T_{2}=N$. Let $2^{A}$ be the set of nonempty subsets of $A$. Assume that the preference relation $R^{i}$ of individual $i, i \in N$, is a complete, antisymmetric and transitive binary relation (or simply a linear order) on $A$ and let $L=\left\{R_{k}: 1 \leq k \leq m\right.$ ! $\}$ be the set of all linear orders on $A$.

A profile is an $n$-tuple $R^{N}=\left(R^{i}\right)_{i \in N}$ of individual preference relations, one for each individual. The set of all profiles on $N$ will be denoted by $L^{N}$. Similarly profiles on $T_{1}$ and $T_{2}$ will be denoted $R^{T_{1}}$ and $R^{T_{2}}$, respectively.

Definition 1 Given $T \subseteq N$, a social choice function (SCF) is a mapping $f$ from $L^{T}$ to $A$.

In other words, an SCF assigns a single alternative to each profile. We now present the $Y R A$ property more formally.

Definition 2 Given $T_{1}$ and $T_{2}$, an SCF $f$ satisfies YRA if for any $R^{T_{1}} \in$ $L^{T_{1}}$ and $R^{T_{2}} \in L^{T_{2}}$ and for all $x \in A$,

$$
\left[f\left(R^{T_{1}}\right)=x \text { and } f\left(R^{T_{2}}\right)=x\right] \Longrightarrow f\left(R^{N}\right)=x
$$

Alternatively,

Definition 3 Given $T_{1}$ and $T_{2}$, an SCF $f$ violates YRA if there exist $R^{T_{1}} \in$ $L^{T_{1}}, R^{T_{2}} \in L^{T_{2}}$ and $\{x, y\} \subseteq A, x \neq y$, such that

$$
f\left(R^{T_{1}}\right)=x, f\left(R^{T_{2}}\right)=x \text { and } f\left(R^{N}\right)=y
$$

An illustration of this notion will be presented in Example 1.

Now, we need additional notations to present the family of $S C F$ s under study in the present paper. For each $R_{k}$ in $L$, let $n_{k}$ be the total number of individuals in $N$ with preference relation $R_{k}$. In particular with $A=$ $\{x, y, z\}$, the set of linear orders on $A$ is:

$$
R_{1}: x y z, \quad R_{2}: x z y, \quad R_{3}: y x z, \quad R_{4}: y z x, \quad R_{5}: z x y, \quad R_{6}: z y x
$$

Given $B \in 2^{A}$ such that $|B| \geq 2$ and $x \in B$, let $r(B, x, k)$ be the rank, according to $R_{k}$, of $x$ among alternatives in $B$. A scoring vector is a $|B|$ tuple $v=\left(v_{1}, \ldots, v_{r}, \ldots, v_{|B|}\right)$ of real numbers such that $v_{1}=1, v_{|B|}=0$ and for all $r=1, \ldots,|B|-1, v_{r} \geq v_{r+1}$. When $B$ is the issue, each individual gives $v_{r}$ points to the alternative in $B$ he ranks at the $r^{\text {th }}$ position.

Definition 4 Given $B \in 2^{A}, T \subseteq N, R^{T} \in L^{T}, x \in B$ and a scoring vector $v \in \mathbb{R}^{|B|}:$

i) $S c\left(B, x, R^{T}, v\right)$, the score of $x$ is defined as follows: $S c\left(B, x, R^{T}, v\right)=$ $\sum_{k=1}^{|B| !} v_{r(B, x, k)} \times n_{k}$ 
ii) with $\widehat{B}=\left\{x \in B: S c\left(B, y, R^{T}, v\right) \geq S c\left(B, x, R^{T}, v\right)\right.$ for all $\left.y \in B\right\}$ as the set of alternatives with the smallest score, $l\left(B, R^{T}, v\right)$ is the losing alternative and is such that $l\left(B, R^{T}, v\right)=$ $\left\{\begin{array}{l}\widehat{B} \text { if } \widehat{B} \text { is a singleton, } \\ g(\widehat{B}) \text { otherwise, } \\ \text { where } g \text { is a mechanism used to break ties among alternatives in } \widehat{B} .\end{array}\right.$

Note that the mechanism $g$ introduced in the definition above is still quite general and can take different forms: a chance mechanism, the power given to a chairman, the lexicographic order of the alternatives, etc. We will later give precision about the type of mechanism we use in this paper.

In social choice processes using positional rules, the winning alternative is the one with the highest score, as stated in the following definition.

Definition 5 Let $B \in 2^{A}, T \subseteq N$ and a scoring vector $v \in \mathbb{R}^{|B|}$, a positional rule (PR) is a social choice function $f$ such that

$\forall R^{T} \in L^{T}, \forall x \in B, \quad f\left(R^{T}\right)=x$ if $\left[S c\left(B, x, R^{T}, v\right) \geq S c\left(B, y, R^{T}, v\right)\right.$ $\forall y \in B, x \neq y]$, with ties broken by some mechanism.

From the definitions above, it appears that given some issue $B$, a $P R$ is defined by a vector $v \in \mathbb{R}^{|B|}$. We can then express three usual procedures: plurality rule if $v=(1,0, \ldots, 0)$; antiplurality rule if $v=(1, \ldots, 1,0)$ and Borda rule if $v=\left(1, \frac{m-2}{m-1}, \ldots, \frac{m-r}{m-1}, \ldots, \frac{1}{m-1}, 0\right)$.

We now introduce the sequential positional rules $(S P R)$ under consideration all along our study.

Let $V^{A}=\left\{v^{m}, \ldots, v^{|B|}, \ldots, v^{2}\right\}$ is a collection of scoring vectors, each vector $v^{|B|}$ being associated with each possible cardinality $|B|$ of the subset $B \subseteq A,|B| \geq 2$. At the first step of the sequential process, scores are computed using the vector $v^{m}$ and the losing alternative is eliminated. In the next step, vector $v^{m-1}$ is used to compute the scores and again the losing alternative is eliminated. The sequential process is repeated until a simple majority winner is obtained (see Lepelley 1996).

More formally,

Definition 6 A sequential positional rule (SPR) is a social choice function $f$ such that given $B \subseteq A, R^{N} \in L^{N}$ and $V^{A}=\left\{v^{m}, \ldots, v^{|B|}, \ldots, v^{2}\right\}$, $f\left(R^{N}\right)=A_{m}$, with $A_{m}$ sequentially defined in the following way:

$$
\begin{aligned}
& A_{1}=A \\
& A_{2}=A-l\left(A_{1}, R^{N}, v^{m}\right) \\
& A_{|B|+1}=A_{|B|}-l\left(A_{|B|}, R^{N}, v^{m-|B|+1}\right) \\
& A_{m}=A_{m-1}-l\left(A_{m-1}, R^{N}, v^{2}\right) \text {, with }\left|A_{m}\right|=1
\end{aligned}
$$


In order to illustrate this definition, let us consider the three-alternative case. We then have $v^{A}=\left\{v^{3}, v^{2}\right\}$, with $v^{3}=(1, \lambda, 0), 0 \leq \lambda \leq 1$, where $1, \lambda$ and 0 are the scores of the alternatives ranked first, second and third, respectively, in individual preference relations in the first step, and $v^{2}=$ $(1,0)$. More generally, given a profile of individual preferences, the total score of an alternative is the sum of individual scores, over the whole set of individuals. A $P R$ selects the alternative with the highest score. As a difference, an $S P R$ first eliminates the alternative with the smallest score at the first step, and then selects the alternative with the highest score at the new step, among the remaining ones. Note that with three alternatives, the second step is simply a pairwise majority contest between the two remaining alternatives. Also note that for $\lambda$ equal to 0,1 , or $1 / 2$ in $v^{3}$, we obtain Hare's Procedure $(H P)$, Coombs Procedure $(C P)$ and Iterative Borda Procedure $(I B P)$, respectively.

Smith (1973) studies iterative - as distinguished from sequential - positional rules and he shows that they violate $Y R A$. Under iterative positional rules, at each step the scoring vector changes only with respect to the number of alternatives, while for sequential positional voting rules, there is no fixed relation between two scoring vectors of different steps: for example, we may use plurality at step 1 and antiplurality at step 2, etc. Iterative positional rules are thus special cases of sequential positional rules. In the next section, we shall show that all $S P R$ s violate $Y R A$ provided that $|A| \geq 3$ and $n \geq 15$.

An illustration of the violation of $Y R A$ by $S P R \mathrm{~s}$, is given in Example 1.

Example 1 Suppose the $S P R$ is the Hare procedure, that is $v^{A}=\left\{v^{3}, v^{2}\right\}$, with $v^{3}=(1,0,0)$ and $v^{2}=(1,0)$. Let $A=\{x, y, z\}, T_{1}, T_{2} \subseteq N$, and assume that $R^{T_{1}} \in L^{T_{1}}$ and $R^{T_{2}} \in L^{T_{2}}$ are as below:

\begin{tabular}{|c|c|c|c|c|c|c|c|c|c|c|c|}
\hline \multicolumn{6}{|c|}{$R^{T_{1}}$} & \multicolumn{6}{|c|}{$R^{T_{2}}$} \\
\hline 0 & 16 & 25 & 0 & 15 & 0 & 0 & 15 & 10 & 0 & 20 & 0 \\
\hline$x$ & $x$ & $y$ & $y$ & $z$ & $z$ & $x$ & $x$ & $y$ & $y$ & $z$ & $z$ \\
\hline$y$ & $z$ & $x$ & $z$ & $x$ & $y$ & $y$ & $z$ & $x$ & $z$ & $x$ & $y$ \\
\hline$z$ & $y$ & $z$ & $x$ & $y$ & $x$ & $z$ & $y$ & $z$ & $x$ & $y$ & $x$ \\
\hline
\end{tabular}

Then the scores are as follows

\begin{tabular}{|c|c|c|}
\hline \multicolumn{3}{|c|}{ Separate groups } \\
\hline \multirow{4}{*}{$1^{\text {rst }}$ Step } & $\begin{array}{c}T_{1} \\
S c\left(A, R^{T_{1}} y^{3}\right)=16\end{array}$ & $\begin{array}{c}T_{2} \\
S_{c}\left(A x R^{T_{2}} v^{3}\right)=15\end{array}$ \\
\hline & $S c\left(A, y, R^{T_{1}}, v^{3}\right)=25$ & $S c\left(A, y, R^{T_{2}}, v^{3}\right)=10$ \\
\hline & $S c\left(A, z, R^{T_{1}}, v^{3}\right)=15$ & $S c\left(A, z, R^{T_{2}}, v^{3}\right)=20$ \\
\hline & Loser: $z$ & Loser: $y$ \\
\hline
\end{tabular}




$2^{\text {nd }}$ Step $\left\{\begin{array}{cc|}S c\left(A-\{z\}, x, R^{T_{1}}, v^{2}\right)=31 & S c\left(A-\{y\}, x, R^{T_{2}}, v^{2}\right)=25 \\ S c\left(A-\{z\}, y, R^{T_{1}}, v^{2}\right)=25 & S c\left(A-\{y\}, z, R^{T_{2}}, v^{2}\right)=20 \\ \text { Winner: } x & \text { Winner: } x \\ \hline\end{array}\right.$

The whole electorate: $N=T_{1} \cup T_{2}$

$1^{\text {rst }}$ Step $\left\{\begin{array}{c}S c\left(A, x, R^{N}, v^{3}\right)=31 \\ S c\left(A, y, R^{N}, v^{3}\right)=35 \\ S c\left(A, z, R^{N}, v^{3}\right)=35 \\ \text { Loser: } x\end{array}\right.$

$2^{\text {nd }}$ Step $\left\{\begin{array}{c}S c\left(A-\{x\}, y, R^{N}, v^{2}\right)=35 \\ S c\left(A-\{x\}, z, R^{N}, v^{2}\right)=66 \\ \text { Winner: } z\end{array}\right.$

It appears that the Hare procedure violates YRA: $f\left(R^{T_{1}}\right)=x, f\left(R^{T_{2}}\right)=$ $x$ but $f\left(R^{N}\right)=z$.

In the next section, we will use the notions introduced above in order to prove our result on the violation of $Y R A$ by $S P R \mathrm{~s}$.

\section{General results}

The aim of this section is to identify $S P R$ s that violate $Y R A$ and conditions on the number $n$ of the voters, at which the phenomenon is susceptible to arise. We first consider situations at which such violations can occur for all possible scoring vectors - and it appears that this is the case roughly as soon as the number of voters is equal to 13 or at least 15 - and then, we discuss the case of electorates with less than 13 voters.

Proposition 1 In three-candidate elections with 13 voters or at least 15 voters, all $\mathrm{SPR}$ s violate Young reinforcement axiom.

Proof Let $f$ be an SPR associated with the collection of scoring vectors $V^{A}=\{(1, \lambda, 0),(1,0)\}$.

Case 1: Suppose that $1 \geq \lambda>0$, and $n$ is odd. By assumption on $n$, there exists a non negative integer $p$ such that $n=13+2 p$. Consider the following profiles:

\begin{tabular}{|c|c|c|c|c|c|c|c|c|c|c|c|}
\hline \multicolumn{6}{|c|}{$R^{T_{1}}$} & \multicolumn{6}{|c|}{$R^{T_{2}}$} \\
\hline $2+p$ & 0 & $1+p$ & 0 & 0 & 0 & 0 & 3 & 3 & 0 & 1 & 3 \\
\hline$x$ & $x$ & $y$ & $y$ & $z$ & $z$ & $x$ & $x$ & $y$ & $y$ & $z$ & $z$ \\
\hline$y$ & $z$ & $x$ & $z$ & $x$ & $y$ & $y$ & $z$ & $x$ & $z$ & $x$ & $y$ \\
\hline$z$ & $y$ & $z$ & $x$ & $y$ & $x$ & $z$ & $y$ & $z$ & $x$ & $y$ & $x$ \\
\hline
\end{tabular}

At the first step and profile $R^{T_{1}}, z$ collects 0 point and is ruled out of the process. For the second step, $x$ defeats $y$ with $2+p$ favorable votes against $1+p$ for $y$. That is $f\left(R^{T_{1}}\right)=x$. 
At the first step and $R^{T_{2}}, x, y$ and $z$ obtain respectively $3+4 \lambda$ points, $3+3 \lambda$ points and $4+3 \lambda$ points. Since $\lambda>0, y$ gets the smallest number of points and is then ruled out of the process. At the second step, $x$ defeats $z$ with 6 favorable votes against 4 for $z$. That is $f\left(R^{T_{2}}\right)=x$.

At the first step and $R^{N}, x, y$ and $z$ gather respectively $5+p+(p+5) \lambda$ points, $4+p+(p+5) \lambda$ points and $4+3 \lambda$ points. Since $\lambda>0$ and $p \geq 0, z$ gets the smallest number of points and is ruled out of the process. At the second step, $y$ defeats $x$ with $8+p$ favorable votes against $5+p$ for $x$. That is $f\left(R^{N}\right)=y$.

Case 2: Suppose that $1 \geq \lambda>0$ and $n$ is even. By assumption on $n$, there exists a non negative integer $p$ such that $n=16+2 p$. Consider the following profiles:

\begin{tabular}{|c|c|c|c|c|c|c|c|c|c|c|c|}
\hline \multicolumn{6}{|c|}{$R^{T_{1}}$} & \multicolumn{6}{|c|}{$R^{T_{2}}$} \\
\hline $2+p$ & 0 & $1+p$ & 0 & 0 & 0 & 0 & 4 & 4 & 0 & 1 & 4 \\
\hline$x$ & $x$ & $y$ & $y$ & $z$ & $z$ & $x$ & $x$ & $y$ & $y$ & $z$ & $z$ \\
\hline$y$ & $z$ & $x$ & $z$ & $x$ & $y$ & $y$ & $z$ & $x$ & $z$ & $x$ & $y$ \\
\hline$z$ & $y$ & $z$ & $x$ & $y$ & $x$ & $z$ & $y$ & $z$ & $x$ & $y$ & $x$ \\
\hline
\end{tabular}

Using very similar arguments as in the previous case one can easily check that $f\left(R^{T_{1}}\right)=x, f\left(R^{T_{2}}\right)=x$ and $f\left(R^{N}\right)=y$.

Case 3: Suppose that $\lambda=0$ and $n$ is odd. Then there exists a non negative integer $p$ such that $n=13+2 p$. Consider the following profiles:

\begin{tabular}{|c|c|c|c|c|c|c|c|c|c|c|c|}
\hline \multicolumn{6}{|c|}{$R^{T_{1}}$} & \multicolumn{6}{|c|}{$R^{T_{2}}$} \\
\hline $3+p$ & 0 & $2+p$ & 0 & 0 & 0 & 3 & 0 & 2 & 0 & 0 & 3 \\
\hline$x$ & $x$ & $y$ & $y$ & $z$ & $z$ & $x$ & $x$ & $y$ & $y$ & $z$ & $z$ \\
\hline$y$ & $z$ & $x$ & $z$ & $x$ & $y$ & $y$ & $z$ & $x$ & $z$ & $x$ & $y$ \\
\hline$z$ & $y$ & $z$ & $x$ & $y$ & $x$ & $z$ & $y$ & $z$ & $x$ & $y$ & $x$ \\
\hline
\end{tabular}

At the first step and $R^{T_{1}}, z$ gets 0 point and is ruled out of the process. At the second step, $x$ defeats $y$ with $3+p$ favorable votes against $2+p$ for $y$. That is $f\left(R^{T_{1}}\right)=x$.

At the first step and $R^{T_{2}}, x, y$ and $z$ get respectively 3 points, 2 points and 3 points. Therefore $y$ gets the smallest amount of points and is then ruled out of the process. At the second step, $x$ defeats $z$ with 5 favorable votes against 3 for $z$. That is $f\left(R^{T_{2}}\right)=x$.

At the first step and $R^{N}, x, y$ and $z$ gather respectively $6+p$ points, $4+p$ points and 3 points. Since $p \geq 0, z$ gets the smallest number of points and is ruled out of the process. At the second step, $y$ defeats $x$ with $7+p$ favorable votes against $6+p$ for $x$. That is $f\left(R^{N}\right)=y$.

Case 4: Suppose that $\lambda=0$ and $n$ is even. By assumption on $n$, there exists a non negative integer $p$ such that $n=16+2 p$. Consider the following 
profiles:

\begin{tabular}{|c|c|c|c|c|c|c|c|c|c|c|c|}
\hline \multicolumn{6}{|c|}{$R^{T_{1}}$} & \multicolumn{6}{|c|}{$R^{T_{2}}$} \\
\hline $3+p$ & 0 & $2+p$ & 0 & 0 & 0 & 0 & 4 & 3 & 0 & 0 & 4 \\
\hline$x$ & $x$ & $y$ & $y$ & $z$ & $z$ & $x$ & $x$ & $y$ & $y$ & $z$ & $z$ \\
\hline$y$ & $z$ & $x$ & $z$ & $x$ & $y$ & $y$ & $z$ & $x$ & $z$ & $x$ & $y$ \\
\hline$z$ & $y$ & $z$ & $x$ & $y$ & $x$ & $z$ & $y$ & $z$ & $x$ & $y$ & $x$ \\
\hline
\end{tabular}

Again, as in the previous case one can easily check that $f\left(R^{T_{1}}\right)=x$, $f\left(R^{T_{2}}\right)=x$ and $f\left(R^{N}\right)=y$.

It the appears that in all cases considered above, all $S P R$ s violate Young reinforcement axiom; and this concludes the proof.

As a direct consequence of the preceding proposition, the following holds:

Proposition 2 With 13 voters or at least 15 voters and at least three candidates, all $\mathrm{SPR}$ s violate the Young reinforcement axiom.

Proof Suppose $A=\left\{x, y, z, a_{4}, a_{5}, \ldots, a_{m}\right\}$ and let $f$ be an $S P R$ associated with a collection of scoring vectors $V^{A}=\left\{v^{m}, \ldots, v^{3}, v^{2}\right\}$, with $v^{2}=(1,0)$ and $v^{3}=(1, \lambda, 0)$. Consider the four distinct cases in the proof of Proposition 1 and the corresponding profiles $R^{T_{1}}$ and $R^{T_{2}}$. Now, construct two new profiles $\underline{R}^{T_{1}}$ and $\underline{R}^{T_{2}}$ from $R^{T_{1}}$ and $R^{T_{2}}$ respectively, in such a way that alternative $a_{4}$ appears at the fourth position in each individual preference relation, $a_{5}$ appears at the fifth position, and so on. Each candidate in $\{x, y, z\}$ gets the same number of points as presented in the proof of Proposition 1. Moreover all candidates in $\{x, y, z\}$ record more points than every candidate in $\left\{a_{4}, a_{5}, \ldots, a_{m}\right\}$ until candidates in $\left\{a_{4}, a_{5}, \ldots, a_{m}\right\}$ are all ruled out of the process. It follows that the two last steps are exactly the same as with $R^{T_{1}}, R^{T_{2}}$ and $R^{N}$ respectively. That is $f\left(\underline{R}^{T_{1}}\right)=x, f\left(\underline{R}^{T_{2}}\right)=x$ and $f\left(\underline{R}^{N}\right)=y$. Consequently, $f$ violates the Young reinforcement axiom.

The two propositions above show that all $S P R$ s violate $Y R A$ when the number of voters is equal to 13 or is at least 15 , provided that the number of alternatives is at least three. Note that there is no

It remains to consider situations with only two alternatives, and electorates with no more than 12 voters (and also $n=14$ ). The discussion below provides answers to these questions.

First, for all $n \in N$, and $|A|=2$, it straightforwardly appears that there exists no $S P R$ which violates $Y R A$.

Second, with three alternatives, a computer based complete enumeration program (available from the authors upon simple request) reveals that there is no $n$ for which all SPRs violate YRA. However, for some $n$ and some $\lambda$, our computation program exhibits cases of violations of $Y R A$. It is obvious that this is also true for four or more alternatives.

Fig. 1 below summarizes these results. It represents, for each $S P R$, the frequency of violation of $Y R A$, with respect to both $n$ ( $n$ is between 1 and 14) and the scoring vector, with $0 \leq \lambda \leq 1$. Specifically, it shows that the 
best rules, according to YRA, are clearly the usual ones: Hare's Procedure, Coombs Procedure and Iterative Borda Procedure; they minimize the frequency of violation of $Y R A$, among all $S P R \mathrm{~s}$.

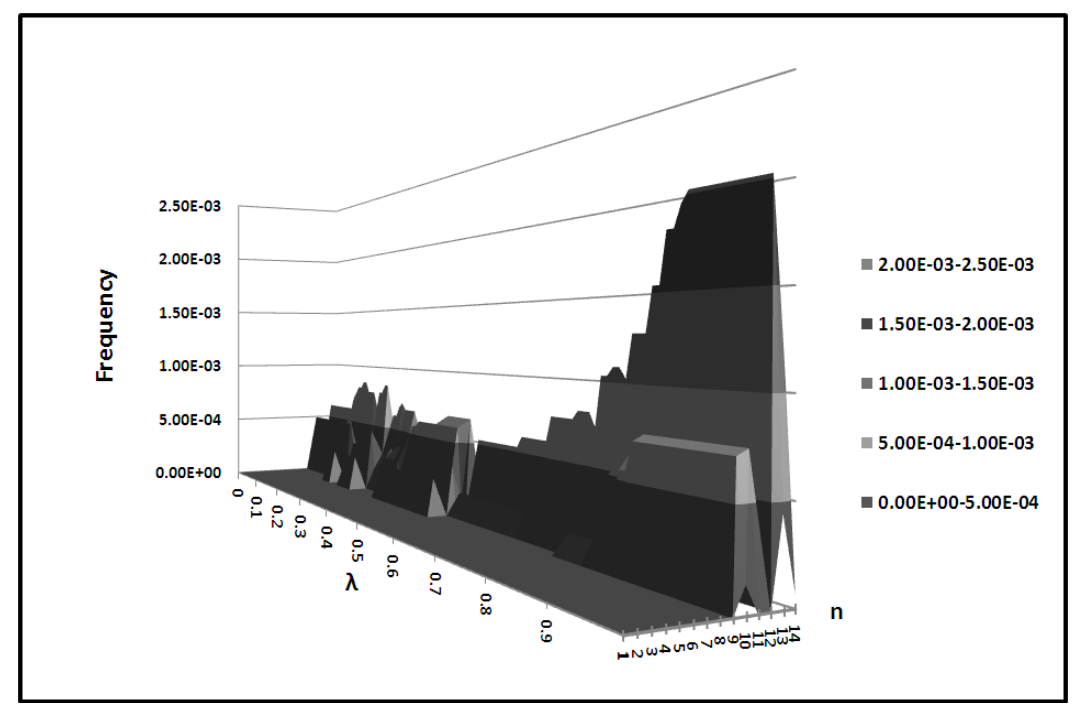

Fig. 1 Violation of $Y R A$ for small values of $n$

for three alternatives, $0 \leq \lambda \leq 1$ and $n=1, \ldots, 14$.

These last results also suggest that one of our main goals in this paper is to evaluate how frequent $S P R$ s violate $Y R A$. In the next section, we focus on the special case of three alternatives.

\section{Violations of reinforcement}

In this section we present a typology of the various preference profiles at which the violation of the $Y R A$ arises. As mentioned above, we only study the three-alternative case. With four or more alternatives, computations are much more involved.

Given $A=\left\{a_{1}, a_{2}, a_{3}\right\}$, there are exactly six linear orders on $A$, labeled below:

$R_{1}: a_{1} a_{2} a_{3}, R_{2}: a_{1} a_{3} a_{2}, R_{3}: a_{2} a_{1} a_{3}, R_{4}: a_{2} a_{3} a_{1}, R_{5}: a_{3} a_{1} a_{2}, R_{6}: a_{3} a_{2} a_{1}$

We first introduce some further notations and definitions. A situation $s^{N}$ is a preference profile obtained from a profile $R^{N}$ by rewriting it as $s^{N}=$ $\left(n_{1}, n_{2}, n_{3}, n_{4}, n_{5}, n_{6}\right)$, where for each $k=\{1, \ldots, 6\}, n_{k}$ is the number of individuals in $N$ with preference relation $R_{k}$. In other words, a situation is a 6 -tuple of natural integers such that $\Sigma_{k=1}^{6} n_{k}=n$. 
In order to take the two disjoint groups $T_{1}$ and $T_{2}$ into consideration, with $j \in\{1,2\}, t^{T_{j}}=\left(t_{1}^{j}, \ldots, t_{6}^{j}\right)$ denotes a preference profile deduced from a profile $R^{T_{j}}$ where $t_{k}^{j}$ is the number of individuals in $T_{j}$ with preference relation $R_{k}$, and $\Sigma_{k=1}^{6} t_{k}^{j}=\left|T_{j}\right|$. Note that since $T_{1} \cup T_{2}=N, t_{k}^{1}+t_{k}^{2}=n_{k}$.

We now specify the mechanism we use in this paper in order to break ties among alternatives in $\widehat{B}$ (see Definition 4), that is the lexicographic order; in other words, ties are broken in favor of the alternatives with the smallest index, which can be written as follows:

$$
a_{h} \text { beats } a_{k} \Leftrightarrow\left\{\begin{array}{l}
h<k \Rightarrow S c\left(B, a_{h}, R^{T}, v\right) \geq S c\left(A, a_{k}, R^{T}, v\right) \\
k<h \Rightarrow S c\left(B, a_{h}, R^{T}, v\right)>S c\left(A, a_{k}, R^{T}, v\right)
\end{array}\right.
$$

where $T \subseteq N$.

Notice that one can imagine many other ways to break ties: a random mechanism, a chairman whose vote breaks ties, etc. The mechanism chosen here - the lexicographic order - has at least two advantages: it avoids introducing chance in the determination of the outcome, and it is compatible with the anonymity of the rules since it preserves the equalitity of treatment of all voters. Further, as the number of voters rises, impact of such a mechanism becomes marginal.

Note that when the number of alternatives is reduced to three, under an $S P R$, there are at most two steps in order to determine the winning alternative. In situations with only one single step - that is, with an outcome selected after a unique step - the winning alternative is called the first step winner. We then have the proposition below.

Proposition 3 Let $A=\left\{a_{1}, a_{2}, a_{3}\right\}, B \subseteq A, T$ a constituency, $R^{T} \in L^{T}$ and consider an SPR associated with $V^{\bar{A}}=\{(1, \lambda, 0),(1,0)\}$. Then for all $h \in\{1,2,3\}$, alternative $a_{h}$ is the first step winner if

$$
\begin{array}{r}
S c\left(B, a_{h}, R^{T}, v^{3}\right)>\frac{(1+\lambda)|T|}{2} \\
\text { with }(1+\lambda)|T|=\sum_{i=1}^{3} S c\left(B, a_{i}, R^{T}, v^{3}\right)
\end{array}
$$

Proof Since $\lambda \in[0,1]$, we distinguish two cases: (i) First suppose $\lambda=1$. Then, $a_{h}$ cannot be selected at the first step. Since the sum of the scores of the three alternatives is equal to $(1+\lambda)|T|=2|T|$, it follows that in order to be selected at the first step, $a_{h}$ should have a score strictly higher than $\frac{2|T|}{2}=$ $|T|$, which is impossible. (ii) Now suppose $\lambda \in\left[0,1\left[\right.\right.$. If $S c\left(B, a_{h}, R^{T}, v^{3}\right)>$ $\frac{(1+\lambda)|T|}{2}$, then clearly the score of $a_{h}$ must be strictly higher than the score of each of the two other alternatives in the first step. Furthermore, if $S c\left(B, a_{h}, R^{T}, v^{3}\right)>\frac{(1+\lambda)|T|}{2}$, then $a_{h}$ is a Condorcet winner, i.e. it beats all the other alternatives in the second step. Without loss of generality, assume $h=3: S c\left(B, a_{3}, R^{T}, v^{3}\right)>\frac{(1+\lambda)|T|}{2}$; then, we must have $\lambda t_{2}+$ 
$\lambda t_{4}+t_{5}+t_{6}>\frac{(1+\lambda)|T|}{2}$, which can be rewritten $\lambda t_{2}+\lambda t_{4}+t_{5}+t_{6}>$ $\frac{(1+\lambda)}{2}\left(t_{1}+t_{2}+t_{3}+t_{4}+t_{5}+t_{6}\right)$, or $\frac{(1-\lambda)}{2} t_{5}+\frac{(1-\lambda)}{2} t_{6}>\frac{(1+\lambda)}{2} t_{1}+\frac{(1-\lambda)}{2} t_{2}+$ $\frac{(1+\lambda)}{2} t_{3}+\frac{(1-\lambda)}{2} t_{4}$, which gives $t_{5}+t_{6}>\frac{(1+\lambda)}{(1-\lambda)} t_{1}+t_{2}+\frac{(1+\lambda)}{(1-\lambda)} t_{3}+t_{4}$, and finally $t_{4}+t_{5}+t_{6}>\frac{(1+\lambda)}{(1-\lambda)} t_{1}+t_{2}+\frac{(1+\lambda)}{(1-\lambda)} t_{3}+2 t_{4}$. Besides, since $\lambda \in[0,1[$, then $\frac{(1+\lambda)}{(1-\lambda)} \in\left[1,+\infty\left[\right.\right.$, hence the last inequality above implies $t_{4}+t_{5}+$ $t_{6}>t_{1}+t_{2}+t_{3}+2 t_{4}$. And from the fact that $t_{4} \geq 0$, it follows that $t_{4}+t_{5}+t_{6}>t_{1}+t_{2}+t_{3}$, which means that $a_{3}$ beats $a_{1}$ in a pairwise contest. The same reasoning applies for $a_{3}$ and $a_{2}$. Thus, for any alternative $a_{h}$, if $S c\left(B, a_{h}, R^{T}, v^{3}\right)>\frac{(1+\lambda)|T|}{2}$, then the alternatives different from $a_{h}$ cannot be selected, even if we proceed with a second step between the two alternatives with the highest scores. And this completes the proof.

If $a_{h}$ wins with two steps, the inequalities susceptible to occur in each step are as follows:

$$
\begin{array}{ll}
\text { First step } & \begin{cases}S c\left(B, a_{h}, R^{T}, v^{3}\right) \leq \frac{(1+\lambda)|T|}{2} & (\alpha) \\
S c\left(B, a_{h}, R^{T}, v^{3}\right) \geq S c\left(A, a_{k}, R^{T}, v^{3}\right) & \text { if } h<k \quad(\beta) \\
S c\left(B, a_{h}, R^{T}, v^{3}\right) S c\left(A, a_{k}, R^{T}, v^{3}\right) & \text { if } h>k \quad(\gamma) \\
S c\left(B, a_{j}, R^{T}, v^{3}\right) \geq S c\left(A, a_{k}, R^{T}, v^{3}\right) & \text { if } j<k \quad(\delta) \\
S c\left(B, a_{j}, R^{T}, v^{3}\right)>S c\left(A, a_{k}, R^{T}, v^{3}\right) & \text { if } j>k(\varepsilon)\end{cases} \\
\text { Second step }\left\{\begin{array}{lll}
S c\left(B, a_{h}, R^{T}, v^{2}\right) \geq S c\left(A, a_{j}, R^{T}, v^{2}\right) & \text { if } h<j(\zeta) \\
S c\left(B, a_{h}, R^{T}, v^{2}\right)>S c\left(A, a_{j}, R^{T}, v^{2}\right) & \text { if } h>j(\eta)
\end{array}\right.
\end{array}
$$

Below, we use sets of the Greek letters above to denote situations where any combination of inequalities above occurs; for example $\{\alpha, \beta, \gamma\}$ means that inequalities $(\alpha),(\beta)$ and $(\gamma)$ occur simultaneously.

Definition 7 Let $A=\left\{a_{1}, a_{2}, a_{3}\right\}, B \subseteq A, T$ a constituency, $R^{T} \in L^{T}$ and consider an SPR associated with $V^{\bar{A}}=\{(1, \lambda, 0),(1,0)\}$.

i) For all distinct $h, k, j \in\{1,2,3\}$, alternative $a_{h}$ is selected at the second step and is called the "second step winner" if any one of the following cases occurs:

$\begin{array}{cccc}\text { Case 1 } & \text { Case 2 } & \text { Case 3 } & \text { Case 4 } \\ \{\alpha, \beta, \delta, \zeta\} & \{\alpha, \beta, \delta, \eta\} & \{\alpha, \beta, \varepsilon, \zeta\} & \{\alpha, \beta, \varepsilon, \eta\}\end{array}$

\section{Case $5 \quad$ Case $6 \quad$ Case $7 \quad$ Case 8}

$\{\alpha, \gamma, \delta, \zeta\} \quad\{\alpha, \gamma, \delta, \eta\} \quad\{\alpha, \gamma, \varepsilon, \zeta\} \quad\{\alpha, \gamma, \varepsilon, \eta\}$

ii) Alternative $a_{h}$ is called the

$\{$ "challenger" if it is beaten at the second step,

"the loser" if it is beaten at the first step.

We then distinguish six potential possibilities, for the violation of $Y R A$ to occur:

$P_{1}$ : An alternative is "the first step winner" in both constituencies;

$P_{2}$ : An alternative is "the second step winner" in both constituencies, with the same "challenger"; 
$P_{3}$ : An alternative is "the first step winner" in one constituency and "the second step winner" in the other one. The "challenger" of the second constituency is selected in the union of the two constituencies;

$P_{4}$ : An alternative is "the first step winner" in one constituency and "the second step winner" in the other one. The "loser" of the second constituency is selected in the union of the two constituencies, with the "challenger" of the second constituency as the challenger of the whole electorate;

$P_{5}$ : An alternative is "the first step winner" in one constituency and "the second step winner" in the other one. The "loser" of the second constituency is selected in the union of the two constituencies, with the "the first step winner" as the "challenger" of the whole electorate;

$P_{6}$ : An alternative is "the second step winner" in both constituencies with two different "challengers".

We then show that some of the possibilities above can actually lead to the violation of $Y R A$, while others cannot. We begin with cases at which $Y R A$ is not violated.

Proposition 4 Let $A=\left\{a_{1}, a_{2}, a_{3}\right\}, B \subseteq A, T_{j} \subseteq N, j=1,2 . R^{T_{1}} \in L^{T_{1}}$ and consider an SPR associated with $V^{A}=\{(1, \lambda, 0),(1,0)\}, 0 \leq \lambda \leq 1$. Then, the SPR does not violate YRA if any one of the following possibilities occurs: $P_{1}, P_{2}, P_{3}, P_{4}$.

Proof Without loss of generality, suppose $a_{1}$ is the winner in both $T_{1}$ and $T_{2}$. The proof for alternatives $a_{2}$ and $a_{3}$ is very similar and is then omitted. We successively consider possibilities $P_{1}, P_{2}, P_{3}$ and $P_{4}$.

- $P_{1}: a_{1}$ is the first step winner in both constituencies. From the proof of Proposition 3 (i), case $\lambda=1$ is not possible, then $0 \leq \lambda<1$, and in particular, the two following inequalities are true: $t_{1}^{1}+t_{2}^{1}+\lambda t_{3}^{1}+\lambda t_{5}^{1}>$ $\frac{(1+\lambda)\left|T_{1}\right|}{2}(1)$ and $t_{1}^{2}+t_{2}^{2}+\lambda t_{3}^{2}+\lambda t_{5}^{2}>\frac{(1+\lambda)\left|T_{2}\right|}{2}(2)$. Since $t_{k}^{1}+t_{k}^{2}=n_{k}$, if we add (1) and (2), we have $n_{1}+n_{2}+\lambda n_{3}+\lambda n_{5}>\frac{(1+\lambda) n}{2}$. It follows that $a_{1}$ is the first step winner in $N$. Hence, violation of $Y R A$ is not susceptible to occur.

- $P_{2}: a_{1}$ is the second step winner with $a_{2}$ as the challenger in both constituencies. Then, the following inequalities are true:

$$
\begin{aligned}
& \left\{T _ { 1 } \quad \text { Step 1: } \left\{\begin{array}{l}
t_{1}^{1}+t_{2}^{1}+\lambda t_{3}^{1}+\lambda t_{5}^{1} \leq \frac{(1+\lambda)\left|T_{1}\right|}{(1+\lambda)\left|T_{1}\right|} \\
\lambda t_{1}^{1}+t_{3}^{1}+t_{4}^{1}+\lambda t_{6}^{1} \leq \frac{(1+2}{2} \\
\lambda t_{2}^{1}+\lambda t_{4}^{1}+t_{5}^{1}+t_{6}^{1} \leq \frac{(1+\lambda)\left|T_{1}\right|}{2} \\
t_{1}^{1}+t_{2}^{1}+t_{3}^{1}+t_{5}^{1} \geq \lambda t_{2}^{1}+\lambda t_{4}^{1}+t_{5}^{1}+t_{6}^{1} \\
\lambda t_{1}^{1}+t_{3}^{1}+t_{4}^{1}+\lambda t_{6}^{1} \geq \lambda t_{2}^{1}+\lambda t_{4}^{1}+t_{5}^{1}+t_{6}^{1}
\end{array}\right.\right. \\
& \text { Step 2: }\left\{t_{1}^{1}+t_{2}^{1}+t_{5}^{1} \geq t_{3}^{1}+t_{4}^{1}+t_{6}^{1}\right. \\
& \left\{T _ { 2 } \quad \text { Step 1: } \left\{\begin{array}{l}
t_{1}^{2}+t_{2}^{2}+\lambda t_{3}^{2}+\lambda t_{5}^{2} \leq \frac{(1+\lambda)\left|T_{1}\right|}{2} \\
\lambda t_{1}^{2}+t_{3}^{2}+t_{4}^{2}+\lambda t_{6}^{2} \leq \frac{(1+\lambda)\left|T_{2}\right|}{2} \\
\lambda t_{2}^{2}+\lambda t_{4}^{2}+t_{5}^{2}+t_{6}^{2} \leq \frac{(1+\lambda)\left|T_{3}\right|}{2} \\
t_{1}^{2}+t_{2}^{2}+\lambda t_{3}^{2}+\lambda t_{5}^{2} \geq \lambda t_{2}^{2}+\lambda t_{4}^{2}+t_{5}^{2}+t_{6}^{2} \\
\lambda t_{1}^{2}+t_{3}^{2}+t_{4}^{2}+\lambda t_{6}^{2} \geq \lambda t_{2}^{2}+\lambda t_{4}^{2}+t_{5}^{2}+t_{6}^{2}
\end{array}\right.\right.
\end{aligned}
$$


Then, when we add (3) and (4),

$$
\left\{\quad \text { Step 1: } \left\{\begin{array}{l}
\lambda n_{1}+n_{3}+n_{4}+\lambda n_{6} \leq \frac{(1+\lambda) n}{2} \\
\lambda n_{1}+n_{3}+n_{4}+\lambda n_{6} \leq \frac{(1+\lambda) n}{2} \\
\lambda n_{2}+\lambda n_{4}+n_{5}+n_{6} \leq \frac{(1+\lambda) n}{2} \\
n_{1}+n_{2}+\lambda n_{3}+\lambda n_{5} \geq \lambda n_{2}+\lambda n_{4}+n_{5}+n_{6} \\
\lambda n_{1}+n_{3}+n_{4}+\lambda n_{6} \geq \lambda n_{2}+\lambda n_{4}+n_{5}+n_{6}
\end{array}\right.\right.
$$

Step 2: $\left\{n_{1}+n_{2}+n_{5} \geq n_{3}+n_{4}+n_{6}\right.$

Hence $a_{1}$ is the second step winner in $N$. And it follows that $Y R A$ cannot be violated.

- $P_{3}: a_{1}$ is the first step winner in $T_{1}$ and the second step winner with $a_{2}$ as the challenger in $T_{2}$. Clearly, $0 \leq \lambda<1$ and in particular, $t_{1}^{1}+t_{2}^{1}+\lambda t_{3}^{1}+$ $\lambda t_{5}^{1}>\frac{(1+\lambda)\left|T_{1}\right|}{2}(5)$ and $t_{1}^{2}+t_{2}^{2}+t_{5}^{2} \geq \frac{\left|T_{2}\right|}{2}$ (6). We show that $a_{2}$ cannot be elected in $N$. Suppose on the contrary that $a_{2}$ is selected in $N$ : in step 2 , we then have $n_{3}+n_{4}+n_{6}>\frac{n}{2}$, which can be rewritten $\underbrace{t_{3}^{2}+t_{4}^{2}+t_{6}^{2}}_{(a)}+$

$\underbrace{t_{3}^{1}+t_{4}^{1}+t_{6}^{1}}_{(b)}>\frac{n}{2}$. Now, consider terms $(a)$ and $(b)$ separately. We begin with (a): from (6), $t_{3}^{2}+t_{4}^{2}+t_{6}^{2}<\frac{\left|T_{2}\right|}{2}$. Now consider (b). We show that $t_{3}^{1}+t_{4}^{1}+t_{6}^{1}<\frac{\left|T_{1}\right|}{2}$ : from (5), $t_{1}^{1}+t_{2}^{1}+\lambda t_{3}^{1}+\lambda t_{5}^{1}>\frac{(1+\lambda)\left|T_{1}\right|}{2}$, which is equivalent to $t_{1}^{1}+t_{2}^{1}+\lambda t_{3}^{1}+\lambda t_{5}^{1}>\frac{(1+\lambda)}{2}\left(t_{1}^{1}+t_{2}^{1}+t_{3}^{1}+t_{4}^{1}+t_{5}^{1}+t_{6}^{1}\right)$, and can be rewritten $\frac{(1-\lambda)}{2} t_{1}^{1}+\frac{(1-\lambda)}{2} t_{2}^{1}>\frac{(1-\lambda)}{2} t_{3}^{1}+\frac{(1+\lambda)}{2} t_{4}^{1}+\frac{(1-\lambda)}{2} t_{5}^{1}+\frac{(1+\lambda)}{2} t_{6}^{1}$, or $t_{1}^{1}+t_{2}^{1}>t_{3}^{1}+\frac{(1+\lambda)}{(1-\lambda)} t_{4}^{1}+t_{5}^{1}+\frac{(1+\lambda)}{(1-\lambda)} t_{6}^{1}$, that is $t_{1}^{1}+t_{2}^{1}+t_{5}^{1}>t_{3}^{1}+$ $\frac{(1+\lambda)}{(1-\lambda)} t_{4}^{1}+2 t_{5}^{1}+\frac{(1+\lambda)}{(1-\lambda)} t_{6}^{1}$. Since $0 \leq \lambda<1,1 \leq \frac{(1+\lambda)}{(1-\lambda)} \leq+\infty$; hence $t_{3}^{1}+\frac{(1+\lambda)}{(1-\lambda)} t_{4}^{1}+2 t_{5}^{1}+\frac{(1+\lambda)}{(1-\lambda)} t_{6}^{1} \geq t_{3}^{1}+t_{4}^{1}+t_{6}^{1}$, from which it follows that $t_{1}^{1}+t_{2}^{1}+t_{5}^{1}>t_{3}^{1}+t_{4}^{1}+t_{6}^{1}$, and finally $t_{3}^{1}+t_{4}^{1}+t_{6}^{1}<\frac{\left|T_{1}\right|}{2}$. Consequently, from $(a)$ and $(b)$, we must have:

$\underbrace{t_{3}^{2}+t_{4}^{2}+t_{6}^{2}}_{(a)}+\underbrace{t_{3}^{1}+t_{4}^{1}+t_{6}^{1}}_{(b)}<\frac{\left|T_{1}\right|}{2}+\frac{\left|T_{2}\right|}{2}$, that is $\underbrace{t_{3}^{2}+t_{4}^{2}+t_{6}^{2}}_{(a)}+\underbrace{t_{3}^{1}+t_{4}^{1}+t_{6}^{1}}_{(b)}<$ $\frac{n}{2}$, which is equivalent to $n_{3}+n_{4}+n_{6}<\frac{n}{2}$, a contradiction.

We then conclude that $a_{2}$ cannot be selected in $N$. In other words, violation of $Y R A$ is not susceptible to occur.

$-P_{4}: a_{1}$ is the first step winner in $T_{1}$ and the second step winner with $a_{2}$ as the challenger in $T_{2}$. We will show that $a_{1}$ cannot be the loser in $N$, that is $a_{3}$ cannot be selected in $N$ with $a_{2}$ as the challenger: in particular, $\left\{\begin{array}{l}t_{1}^{1}+t_{2}^{1}+\lambda t_{3}^{1}+\lambda t_{5}^{1}>\lambda t_{1}^{1}+t_{3}^{1}+t_{4}^{1}+\lambda t_{6}^{1} \\ t_{1}^{1}+t_{2}^{1}+\lambda t_{3}^{1}+\lambda t_{5}^{1}>\lambda t_{2}^{1}+\lambda t_{4}^{1}+t_{5}^{1}+t_{6}^{1}\end{array} \quad\right.$ and $t_{1}^{2}+t_{2}^{2}+\lambda t_{3}^{2}+\lambda t_{5}^{2} \geq \lambda t_{2}^{2}+\lambda t_{4}^{2}+t_{5}^{2}+t_{6}^{2}(8)$. Then, in $N$, we have: $n_{1}+n_{2}+$ $\lambda n_{3}+\lambda n_{5}>\lambda n_{2}+\lambda n_{4}+n_{5}+n_{6}$, which means that $S c\left(A, a_{1}, R^{N}, v^{3}\right)>$ $S c\left(A, a_{3}, R^{N}, v^{3}\right)$. Then $a_{1}$ cannot be eliminated at the first step. Again, it follows that there is no violation of $Y R A$.

Proposition 5 Let $A=\left\{a_{1}, a_{2}, a_{3}\right\}, B \subseteq A, T_{j} \subseteq N, j=1,2 . R^{T_{1}} \in L^{T_{1}}$ and consider an SPR associated with $V^{A}=\{(1, \lambda, 0),(1,0)\}, 0 \leq \lambda \leq 1$. 
Then, the SPR is susceptible to violate YRA if any one of the following possibilities occurs: $P_{5}$ and $P_{6}$.

Proof In order to prove our result we present an example for each possibility. Let $T_{1}$ and $T_{2}$ be two constituencies.

- $P_{5}$ : Suppose $a_{1}$ is the first step winner in $T_{1}$ and is the second step winner in $T_{2}$ with $a_{2}$ as the challenger; we show that $a_{3}$ can be selected in $N$. Assume the following situations $t^{T_{1}}=(0,30,0,0,20,0)$ and $t^{T_{2}}=$ $(20,0,0,20,20,0)$ associated with $R^{T_{1}}$ and $R^{T_{2}}$, respectively; then, $s^{N}=$ $(20,30,0,20,40,0)$ and the scores are as follows:

\begin{tabular}{|c|c|c|}
\hline \multicolumn{3}{|c|}{ Separate groups } \\
\hline \multirow{5}{*}{$1^{\text {rst }}$ Step } & $T_{1}$ & $T_{2}$ \\
\hline & $S c\left(A, a_{1}, R^{T_{1}}, v^{3}\right)=30+20 \lambda$ & $S c\left(A, a_{1}, R^{T_{2}}, v^{3}\right)=20+20 \lambda$ \\
\hline & $S c\left(A, a_{2}, R^{T_{1}}, v^{3}\right)=0+0 \lambda$ & $S c\left(A, a_{2}, R^{T_{2}}, v^{3}\right)=20+20 \lambda$ \\
\hline & $S c\left(A, a_{3}, R^{T_{1}}, v^{3}\right)=20+30 \lambda$ & $S c\left(A, a_{3}, R^{T_{2}}, v^{3}\right)=20+20 \lambda$ \\
\hline & Losers: $a_{2}, a_{3}$ & Loser: $a_{3}$ \\
\hline \multirow{3}{*}{$2^{\text {nd }}$ Step } & & $S c\left(A-\left\{a_{3}\right\}, a_{1}, R^{T_{2}}, v^{2}\right)=40$ \\
\hline & & $S c\left(A-\left\{a_{3}\right\}, a_{2}, R^{T_{2}}, v^{2}\right)=20$ \\
\hline & Winner: $a_{1}$ & Winner: $a_{1}$ \\
\hline
\end{tabular}

The whole electorate: $N=T_{1} \cup T_{2}$

$1^{\text {rst }}$ Step $\left\{\begin{array}{c}S c\left(A, a_{1}, R^{N}, v^{3}\right)=50+40 \lambda \\ S c\left(A, a_{2}, R^{N}, v^{3}\right)=20+20 \lambda \\ S c\left(A, a_{3}, R^{N}, v^{3}\right)=40+50 \lambda \\ \text { Loser: } a_{2}\end{array}\right.$

$2^{\text {nd }}$ Step $\left\{\begin{array}{c}S c\left(A-\left\{a_{2}\right\}, a_{1}, R^{N}, v^{2}\right)=50 \\ S c\left(A-\left\{a_{2}\right\}, a_{3}, R^{N}, v^{2}\right)=60 \\ \text { Winner: } a_{3}\end{array}\right.$

It follows that $Y R A$ is violated.

- $P_{6}: a_{1}$ is the second step winner in both constituencies with $a_{2}$ (and $a_{3}$ ) as the challenger in $T_{1}$ (and $T_{2}$, respectively). We show that $a_{2}$ or $a_{3}$ can win in $N$. Assume the following situations $t^{T_{1}}=(18,0,2,18,17,1)$ and $t^{T_{2}}=(2,16,15,2,4,18)$ associated with $R^{T_{1}}$ and $R^{T_{2}}$, respectively; then, $s^{N}=(20,16,17,20,21,19)$ and the scores are as follows: 


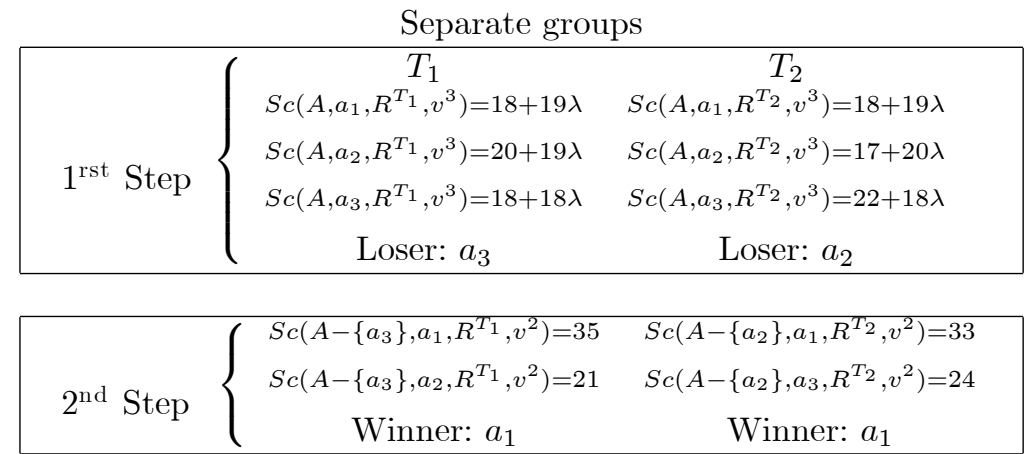

The whole electorate: $N=T_{1} \cup T_{2}$
$1^{\text {rst }}$ Step $\left\{\begin{array}{c}S c\left(A, a_{1}, R^{N}, v^{3}\right)=36+38 \lambda \\ S c\left(A, a_{2}, R^{N}, v^{3}\right)=37+39 \lambda \\ S c\left(A, a_{3}, R^{N}, v^{3}\right)=40+36 \lambda \\ \text { Loser: } a_{1}\end{array}\right.$

$2^{\text {nd }}$ Step $\left\{\begin{array}{c}S c\left(A-\left\{a_{1}\right\}, a_{2}, R^{N}, v^{2}\right)=57 \\ S c\left(A-\left\{a_{1}\right\}, a_{3}, R^{N}, v^{2}\right)=56 \\ \text { Winner: } a_{2}\end{array}\right.$

It follows that $Y R A$ is violated. And this completes the proof.

Retrospectively, it is noticeable that cases of violations of $Y R A$ are closely linked to the fact that the winning alternative in all constituencies is selected with a different challenger. Intuitively, this can be interpreted as a political situation where the two Houses are not "mirror images" of each other.

The results provided in this section will subsequently be used to write systems of inequalities from which we will compute frequencies of violation of $Y R A$.

\section{The likelihood of non reinforceable profiles}

Computer simulations are very often used in social choice in order to determine the frequencies of paradoxes, e. g. Nitzan (1985) or Kelly (1993) among others. The Monte Carlo simulations method, used below, is very useful when a problem cannot be solved analytically. Its principle is simple: (i) firstly, we choose a probabilistic hypothesis, that is the way probabilities are assigned to events; (ii) secondly, for any chosen values of $t_{1}$ and $t_{2}$ (the sizes of constituencies), we draw a given number of voting situations according to the selected hypothesis; voting situations are drawn independently, and (iii) thirdly, for each voting situation, we examine whether the 
situation induces the violation of the $Y R A$ according to the chosen scoring rule. Thus, for each value of $\left(t_{1}, t_{2}\right)$, the estimated probability of violation of $Y R A$ is equal to the ratio

$$
\frac{\text { number of occurrences of violations of } Y R A}{\text { total number of drawn (possibly anonymous) profiles }}
$$

where an anonymous profile is distinguished from a profile in the usual sense by the fact that in the latter the names of the voters matter and in the first one they do not. To illustrate, with three voters and three alternatives, configurations of preferences $(x y z, x z y, y z x)$ and $(x y z, y z x, x z y)$ are distinct profiles in the usual sense in which individuals 2 and 3 have swapped their preferences, but correspond to the same anonymous profile, where one is interested only in the number of individuals with some preference order, and not in the names of these individuals.

In our study, the total number of drawn situations is 100,000 (a greater number does not significantly improve the results). To be precise, note that the values we obtain are not exact probabilities, but rather estimates. For example, a value equal to 0 doesn't necessarily mean that the phenomenon cannot at all occur, but in fact, simply that its probability of occurrence is very small.

The assumption of independence between the two constituencies, while to some extent arbitrary, is however somewhat in accordance with the actual situations of western democracies.

Two traditional probabilistic hypotheses are taken into account: Impartial Culture $(I C)$ and Impartial Anonymous Culture $(I A C)$. Both are based on an equal probability assumption, but not exactly in the same way. According to $I C$, all preference profiles are equally likely: for each voter, every preference order has an equal chance to be drawn $\left(\frac{1}{6}\right.$ in the three-alternative case); and under $I A C$ all anonymous preference profiles are equiprobable: for every possible preference order, the number of voters reporting that order is drawn, in such a way that the total number of voters be equal to $n$. More precisely, for each $n$ and each linear order we draw randomly the number $n_{1}$ of individuals with the first linear order. And then, again randomly, we draw the number $n_{2}$ of individuals with the second linear order between 0 and $n-n_{1}$, and so on. For a detailed discussion of these hypotheses and some others, see Regenwetter et al. (2006).

Then in this section, for each probabilistic hypothesis and each rule under study, two series of results are provided: (a), first, for iterative Borda, Coombs and Hare rules, we present tables of values and graphs corresponding to some values of the total number of voters $t_{1}+t_{2}$, that is $25,50,75$ and 100, and (b) for some specific values of $\lambda$, we then focus on three special cases of bicameral congresses: the French Parliament, the US Congress and the German Parliament.

In the tables, the notation $x \mathrm{E}-y$ is used as an equivalent for $x \times 10^{-y}$, where $x$ and $y$ are real numbers. 
After the presentation of our results with Monte Carlo simulations, we consider cases where the number of individuals is infinitely large, under the $I A C$ hypothesis. Within this framework, we use an analytical method - as distinguished from computer simulations - and provide relations giving the proportion of anonymous profiles vulnerable to the violation of $Y R A$.

\subsection{Impartial Culture}

We shall first consider the case where $n \in\{25,50,75,100\}$ and $t$ (the size of any of the two constituencies) changes from 1 to at most $\frac{n}{2}$ (Tables 1 and 2 ). Note that cases where $t \geq \frac{n}{2}$ are symmetrical to those where $t \leq \frac{n}{2}$. For example, for $n=25$, the results are the same with $t=1$ and $t=24$.

Table 1 ( IC 1) Frequencies of violation of $Y R A$ for Hare,

Iterative Borda and Coombs, with $n=25$ and $n=50$.

\begin{tabular}{|c|c|c|c|c|c|c|}
\hline & \multicolumn{3}{|c|}{$n=25$} & \multicolumn{3}{|c|}{$n=50$} \\
\hline$t$ & HP & IBP & CP & HP & IBP & CP \\
\hline 1 & $>1.00 \mathrm{E}-06$ & $2.90 \mathrm{E}-03$ & $4.16 \mathrm{E}-03$ & $>1.00 \mathrm{E}-06$ & $2.52 \mathrm{E}-03$ & $3.98 \mathrm{E}-03$ \\
\hline 2 & $3.86 \mathrm{E}-03$ & $2.00 \mathrm{E}-03$ & $4.22 \mathrm{E}-03$ & $2.40 \mathrm{E}-03$ & $1.64 \mathrm{E}-03$ & $3.26 \mathrm{E}-03$ \\
\hline 3 & $1.68 \mathrm{E}-02$ & $9.70 \mathrm{E}-03$ & $1.73 \mathrm{E}-02$ & $3.73 E-03$ & $2.70 \mathrm{E}-03$ & $3.72 \mathrm{E}-03$ \\
\hline 4 & $6.82 \mathrm{E}-03$ & $2.16 \mathrm{E}-03$ & $3.02 \mathrm{E}-03$ & $5.83 E-03$ & $2.10 \mathrm{E}-03$ & 4.60E-03 \\
\hline 5 & $6.50 \mathrm{E}-03$ & $1.05 \mathrm{E}-02$ & $1.19 \mathrm{E}-02$ & $5.65 \mathrm{E}-03$ & $3.10 \mathrm{E}-03$ & $7.32 \mathrm{E}-03$ \\
\hline 6 & $8.99 \mathrm{E}-03$ & $1.58 \mathrm{E}-03$ & $8.48 \mathrm{E}-03$ & $5.60 E-03$ & $2.78 \mathrm{E}-03$ & $7.26 \mathrm{E}-03$ \\
\hline 7 & $1.29 \mathrm{E}-02$ & $7.08 \mathrm{E}-03$ & $7.22 \mathrm{E}-03$ & $6.37 \mathrm{E}-03$ & $3.30 \mathrm{E}-03$ & $6.20 \mathrm{E}-03$ \\
\hline 8 & $6.76 \mathrm{E}-03$ & $2.68 \mathrm{E}-03$ & $6.28 \mathrm{E}-03$ & $5.15 E-03$ & $3.00 \mathrm{E}-03$ & $7.86 \mathrm{E}-03$ \\
\hline 9 & $1.51 \mathrm{E}-02$ & $8.50 \mathrm{E}-03$ & $1.31 \mathrm{E}-02$ & $6.78 \mathrm{E}-03$ & $3.56 \mathrm{E}-03$ & $5.52 \mathrm{E}-03$ \\
\hline 10 & $8.40 \mathrm{E}-03$ & $2.70 \mathrm{E}-03$ & $5.46 \mathrm{E}-03$ & $8.15 E-03$ & $4.80 \mathrm{E}-03$ & $8.04 \mathrm{E}-03$ \\
\hline 15 & & & & $6.59 \mathrm{E}-03$ & $4.20 \mathrm{E}-03$ & $7.40 \mathrm{E}-03$ \\
\hline 20 & & & & $6.75 \mathrm{E}-03$ & $3.64 \mathrm{E}-03$ & $9.02 \mathrm{E}-03$ \\
\hline 25 & & & & $6.63 \mathrm{E}-03$ & $2.92 \mathrm{E}-03$ & $6.32 \mathrm{E}-03$ \\
\hline
\end{tabular}

Table 2 ( $I C$ 1) Frequencies of violation of $Y R A$ for Hare, Iterative Borda and Coombs, with $n=75$ and $n=100$.

\begin{tabular}{|c|c|c|c|c|c|c|}
\hline & \multicolumn{3}{|c|}{$n=75$} & \multicolumn{3}{|c|}{$n=100$} \\
\hline$t$ & HP & IBP & CP & HP & IBP & CP \\
\hline 1 & $>1.00 \mathrm{E}-06$ & $1.68 \mathrm{E}-03$ & $2.62 \mathrm{E}-03$ & $>1.00 \mathrm{E}-06$ & $1.44 \mathrm{E}-03$ & $2.60 \mathrm{E}-03$ \\
\hline 2 & $1.99 \mathrm{E}-03$ & $1.54 \mathrm{E}-03$ & $3.02 \mathrm{E}-03$ & $7.24 \mathrm{E}-04$ & $1.04 \mathrm{E}-03$ & $3.90 \mathrm{E}-03$ \\
\hline 3 & $8.34 \mathrm{E}-03$ & $5.62 \mathrm{E}-03$ & $8.70 \mathrm{E}-03$ & $1.69 \mathrm{E}-03$ & $1.48 \mathrm{E}-03$ & $3.78 \mathrm{E}-03$ \\
\hline 4 & $4.36 \mathrm{E}-03$ & $1.68 \mathrm{E}-03$ & $3.32 \mathrm{E}-03$ & $1.62 \mathrm{E}-03$ & $4.60 \mathrm{E}-04$ & $3.00 E-03$ \\
\hline 5 & $5.51 \mathrm{E}-03$ & $5.92 \mathrm{E}-03$ & $9.80 \mathrm{E}-03$ & $2.72 \mathrm{E}-03$ & $1.70 \mathrm{E}-03$ & $5.30 \mathrm{E}-03$ \\
\hline 6 & $5.10 \mathrm{E}-03$ & $2.30 \mathrm{E}-03$ & $5.54 \mathrm{E}-03$ & $3.38 \mathrm{E}-03$ & $1.58 \mathrm{E}-03$ & $6.06 \mathrm{E}-03$ \\
\hline 7 & $8.70 \mathrm{E}-03$ & $5.78 \mathrm{E}-03$ & $7.72 \mathrm{E}-03$ & $3.42 \mathrm{E}-03$ & $1.78 \mathrm{E}-03$ & $5.18 \mathrm{E}-03$ \\
\hline 8 & $4.56 \mathrm{E}-03$ & $2.76 \mathrm{E}-03$ & $7.16 \mathrm{E}-03$ & $2.99 \mathrm{E}-03$ & $1.74 \mathrm{E}-03$ & $6.96 \mathrm{E}-03$ \\
\hline 9 & $7.46 \mathrm{E}-03$ & $5.06 \mathrm{E}-03$ & $9.32 \mathrm{E}-03$ & $3.61 \mathrm{E}-03$ & $2.26 \mathrm{E}-03$ & $5.52 \mathrm{E}-03$ \\
\hline 10 & $6.01 \mathrm{E}-03$ & $3.16 \mathrm{E}-03$ & $6.64 \mathrm{E}-03$ & $4.18 \mathrm{E}-03$ & $1.94 \mathrm{E}-03$ & $6.58 \mathrm{E}-03$ \\
\hline 15 & 8.17E-03 & $4.80 \mathrm{E}-03$ & $7.88 \mathrm{E}-03$ & $4.11 \mathrm{E}-03$ & $2.42 \mathrm{E}-03$ & $6.58 \mathrm{E}-03$ \\
\hline 20 & $5.36 \mathrm{E}-03$ & $2.50 \mathrm{E}-03$ & $6.10 \mathrm{E}-03$ & $4.51 \mathrm{E}-03$ & $1.98 \mathrm{E}-03$ & $8.10 E-03$ \\
\hline 25 & $7.33 \mathrm{E}-03$ & $3.62 \mathrm{E}-03$ & $6.10 \mathrm{E}-03$ & 4.87E-03 & $2.84 \mathrm{E}-03$ & $6.20 \mathrm{E}-03$ \\
\hline 30 & $6.19 \mathrm{E}-03$ & $3.96 \mathrm{E}-03$ & $5.80 \mathrm{E}-03$ & $5.80 \mathrm{E}-03$ & $3.14 \mathrm{E}-03$ & $7.16 \mathrm{E}-03$ \\
\hline 35 & $7.50 \mathrm{E}-03$ & $4.16 \mathrm{E}-03$ & $8.02 \mathrm{E}-03$ & $4.52 \mathrm{E}-03$ & $3.32 \mathrm{E}-03$ & $6.78 \mathrm{E}-03$ \\
\hline 40 & & & & $5.15 \mathrm{E}-03$ & $4.58 \mathrm{E}-03$ & $7.30 \mathrm{E}-03$ \\
\hline 45 & & & & $5.86 \mathrm{E}-03$ & $3.22 \mathrm{E}-03$ & $7.08 \mathrm{E}-03$ \\
\hline 50 & & & & $6.65 \mathrm{E}-03$ & $3.92 \mathrm{E}-03$ & $7.96 \mathrm{E}-03$ \\
\hline
\end{tabular}


For all rules under study, it appears that: (i) for any given value of $n$, and for all values of $t$, frequencies of violation of $Y R A$ are relatively small (generally smaller than $10^{-2}$ ), (ii) for any fixed $n$, those frequencies slightly rise when the value of $t$ rises (fluctuations are due to even or odd values of $t$ ) as illustrated in Fig. 2, 3, 4 and 5 below, (iii) for any given value of $t$, frequencies decrease when $n$ rises, (iv) it follows that frequencies are higher as both constituencies tend to have the same size, (v) finally, although all frequencies are rather small, they are clearly smaller for $I B P$ than for the two other rules, for which they are relatively close.

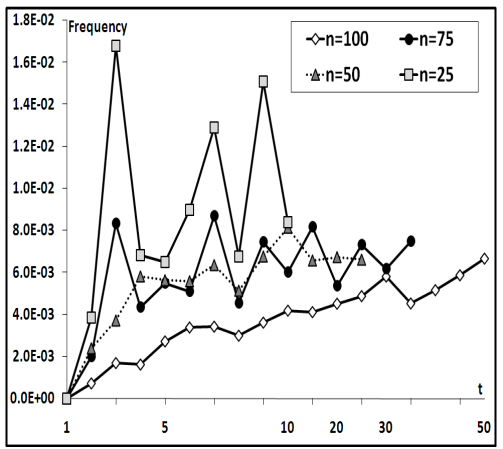

Fig. 2 Frequencies of violation of $Y R A$ under $I C$ for Hare $(H P)$ and $n \in\{25,50,75,100\}$.

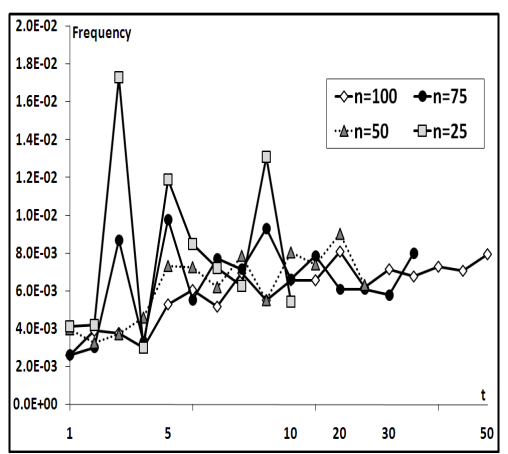

Fig. 4 Frequencies of violation of $Y R A$ under $I C$ for Coombs $(C P)$ and $n \in\{25,50,75,100\}$.

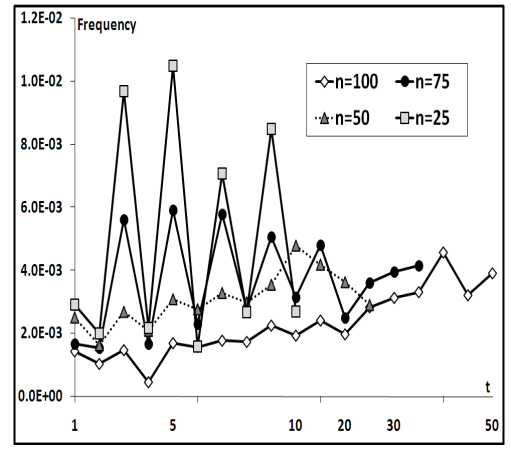

Fig. 3 Frequencies of violation of $Y R A$ under $I C$ for Iterative Borda $(I B P)$ and $n \in\{25,50,75,100\}$.

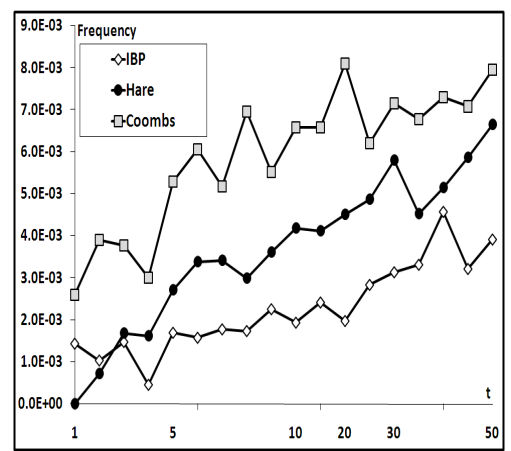

Fig. 5 A comparison of the three rules, under $I C$, for $n=100$.

Now, one natural question is about the limit frequencies as $n$ gets larger. The table and the figure below provide an answer for houses with equal size. Simulations show that (i) values of frequencies are still smaller for $I B P$ than for the two other rules, and (ii) they are relatively stable for $H P$ and $I B P$ while they remain erratic for $C P$. 


\begin{tabular}{|c|ccc|}
\cline { 2 - 4 } \multicolumn{1}{c|}{} & \multicolumn{3}{c|}{$n \geq 100$} \\
100 & HP & IBP & CP \\
250 & $6,65 E-03$ & $3,92 \mathrm{E}-03$ & $7,96 \mathrm{E}-03$ \\
500 & $3,80 \mathrm{E}-03$ & $2,40 \mathrm{E}-03$ & $9,64 \mathrm{E}-03$ \\
750 & $5,24 \mathrm{E}-03$ & $3,60 \mathrm{E}-04$ & $8,40 \mathrm{E}-04$ \\
1000 & $4,98 \mathrm{E}-03$ & $2,38 \mathrm{E}-03$ & $5,20 \mathrm{E}-03$ \\
1000 & $3,00 \mathrm{E}-03$ & $4,20 \mathrm{E}-04$ & $6,00 \mathrm{E}-04$ \\
\hline
\end{tabular}

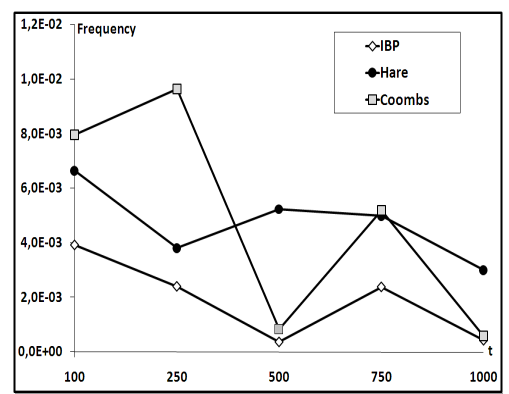

Table 3 and Fig. 6 Frequencies of violation of $Y R A$ for the three rules, under $I C$, with $t=\frac{n}{2}$ and $n=\{100,250,500,750,1000\}$.

We now focus on three special cases of bicameral congresses. The French Parliament is composed of two constituencies: the "Upper House", which is the French Senate (Sénat) with 331 members, and the "Lower House", the French National Assembly (Assemblée Nationale), which has 577 members. For the German Parliament, the two constituencies are the "Federal Council", named the Bundesrat, the size of which is 68 members, and the "Federal Diet" or Bundestag with 598 members. And finally, the US Congress is divided into the Senate on the one hand, the number of members of which is 100, and the House of Representatives on the other hand, with 435 members.

For Table 4 and Fig. 7 below, the size $n$ of the Congress is fixed ( $n=908$ for the French Parliament, and so on for the other countries); only $\lambda$ changes from 0 to 1 , and for $\lambda$ equal to 0,1 , or $1 / 2$, we respectively obtain Hare's Procedure, Coombs Procedure and Iterative Borda Procedure.

Table 4 (IC 3) Theoretical frequencies of violation of $Y R A$ in some Western democracies under different voting rules.

\begin{tabular}{|cccc|cccc|}
\hline$\lambda$ & Germany & France & USA & $\lambda$ & Germany & France & USA \\
0.00 & $1.06 \mathrm{E}-03$ & $1.50 \mathrm{E}-03$ & $1.31 \mathrm{E}-03$ & 0.55 & $6.70 \mathrm{E}-04$ & $1.23 \mathrm{E}-03$ & $1.01 \mathrm{E}-03$ \\
0.05 & $1.13 \mathrm{E}-03$ & $1.67 \mathrm{E}-03$ & $9.90 \mathrm{E}-04$ & 0.60 & $7.2 \mathrm{E}-04$ & $1.58 \mathrm{E}-03$ & $1.39 \mathrm{E}-03$ \\
0.10 & $1.09 \mathrm{E}-03$ & $1.22 \mathrm{E}-03$ & $1.02 \mathrm{E}-03$ & 0.65 & $9.5 \mathrm{E}-04$ & $1.99 \mathrm{E}-03$ & $1.46 \mathrm{E}-03$ \\
0.15 & $9.90 \mathrm{E}-04$ & $1.03 \mathrm{E}-03$ & $7.60 \mathrm{E}-04$ & 0.70 & $7.80 \mathrm{E}-04$ & $2.09 \mathrm{E}-03$ & $1.77 \mathrm{E}-03$ \\
0.20 & $9.00 \mathrm{E}-04$ & $1.20 \mathrm{E}-03$ & $7.60 \mathrm{E}-04$ & 0.75 & $7.90 \mathrm{E}-04$ & $2.08 \mathrm{E}-03$ & $1.92 \mathrm{E}-03$ \\
0.25 & $8.00 \mathrm{E}-04$ & $9.50 \mathrm{E}-04$ & $6.80 \mathrm{E}-04$ & 0.80 & $1.16 \mathrm{E}-03$ & $2.06 \mathrm{E}-03$ & $2.05 \mathrm{E}-03$ \\
0.30 & $5.30 \mathrm{E}-04$ & $7.10 \mathrm{E}-04$ & $5.20 \mathrm{E}-04$ & 0.85 & $1.13 \mathrm{E}-03$ & $1.72 \mathrm{E}-03$ & $2.21 \mathrm{E}-03$ \\
0.35 & $8.20 \mathrm{E}-04$ & $8.00 \mathrm{E}-04$ & $5.40 \mathrm{E}-04$ & 0.90 & $1.06 \mathrm{E}-03$ & $1.73 \mathrm{E}-03$ & $2.15 \mathrm{E}-03$ \\
0.40 & $6.00 \mathrm{E}-04$ & $9.10 \mathrm{E}-04$ & $5.90 \mathrm{E}-04$ & 0.95 & $1.12 \mathrm{E}-03$ & $1.61 \mathrm{E}-03$ & $2.46 \mathrm{E}-03$ \\
0.45 & $7.00 \mathrm{E}-04$ & $1.03 \mathrm{E}-03$ & $7.4 \mathrm{EE}-04$ & 1.00 & $1.45 \mathrm{E}-03$ & $1.62 \mathrm{E}-03$ & $2.60 \mathrm{E}-03$ \\
0.50 & $5.00 \mathrm{E}-04$ & $8.80 \mathrm{E}-04$ & $6.20 \mathrm{E}-04$ & & & & \\
\hline
\end{tabular}




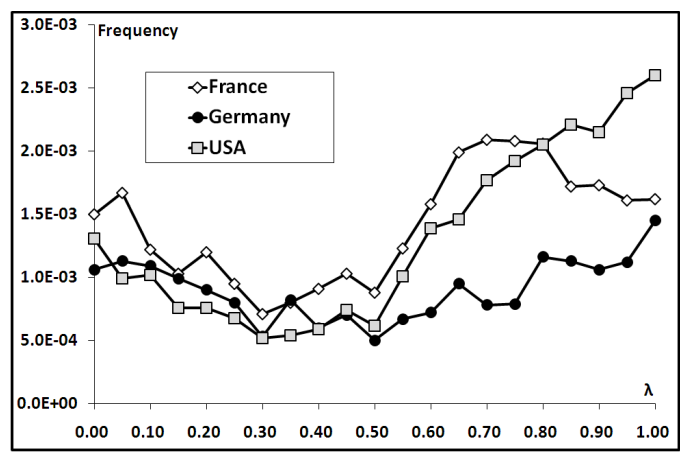

Fig. 7 Comparison of the three Congresses under

$I C$ and under different voting rules $(0 \leq \lambda \leq 1)$.

As already noted above, frequencies are relatively greater with rather equal size constituencies, although they are small for all values of $\lambda$. This is shown in Figure 7 with the German curve which is lower than the US and French curves. Besides, it must also be noticed that the three curves are $U$-shaped, which means that for all of the three Congresses IBP appears as the best procedure among the three classical ones $(H P, I B P$ and $C P$ ) and moreover, $I B P$ is one of the best rules, among all iterative positional rules.

\subsection{Impartial Anonymous Culture}

As for $I C$ above, we consider $n=\{25,50,75,100\}$ and let $t$ change from 1 to $\frac{n}{2}$. Again, the Monte Carlo technique leads to the results provided in Tables 5 and 6 below:

Table 5 (IAC 1) Frequencies of violation of $Y R A$ for Hare, Iterative Borda and Coombs, with $n=25$ and $n=50$.

\begin{tabular}{|c|c|c|c|}
\hline & \multicolumn{3}{|c|}{$n=25$} \\
\hline$t$ & HP & IBP & CP \\
\hline 1 & $>1.00 E-06$ & $>1.00 \mathrm{E}-06$ & $>1.00 E-06$ \\
\hline 2 & $>1.00 \mathrm{E}-06$ & $>1.00 \mathrm{E}-06$ & $>1.00 \mathrm{E}-06$ \\
\hline 3 & 4.00E-05 & $2.80 \mathrm{E}-04$ & $>1.00 E-06$ \\
\hline 4 & $>1.00 \mathrm{E}-06$ & $2.40 E-04$ & $6.00 \mathrm{E}-04$ \\
\hline 5 & $1.00 E-04$ & $>1.00 E-06$ & $5.80 \mathrm{E}-04$ \\
\hline 6 & $4.00 E-05$ & $>1.00 \mathrm{E}-06$ & $5.40 \mathrm{E}-04$ \\
\hline 7 & $>1.00 \mathrm{E}-06$ & $>1.00 \mathrm{E}-06$ & $3.20 \mathrm{E}-04$ \\
\hline 8 & $>1.00 E-06$ & $>1.00 \mathrm{E}-06$ & $4.80 \mathrm{E}-04$ \\
\hline 9 & $1.20 \mathrm{E}-04$ & $>1.00 \mathrm{E}-06$ & $1.60 \mathrm{E}-04$ \\
\hline 10 & $>1.00 E-06$ & $>1.00 E-06$ & 1.00E-04 \\
\hline 15 & & & \\
\hline 20 & & & \\
\hline 25 & & & \\
\hline
\end{tabular}

\begin{tabular}{|c|c|c|}
\hline \multicolumn{3}{|c|}{$n=50$} \\
\hline HP & IBP & CP \\
\hline$>1.00 \mathrm{E}-06$ & $>1.00 \mathrm{E}-06$ & $>1.00 \mathrm{E}-06$ \\
\hline 6.00E-05 & $>1.00 \mathrm{E}-06$ & $>1.00 \mathrm{E}-06$ \\
\hline 6.00E-05 & $>1.00 \mathrm{E}-06$ & $2.00 \mathrm{E}-05$ \\
\hline 4.00E-05 & $>1.00 \mathrm{E}-06$ & $8.00 \mathrm{E}-05$ \\
\hline 6.00E-05 & $>1.00 \mathrm{E}-06$ & $1.60 \mathrm{E}-04$ \\
\hline $6.00 \mathrm{E}-05$ & $>1.00 \mathrm{E}-06$ & $2.40 \mathrm{E}-04$ \\
\hline 8.00E-05 & $>1.00 \mathrm{E}-06$ & $2.00 \mathrm{E}-04$ \\
\hline $1.60 \mathrm{E}-04$ & $>1.00 \mathrm{E}-06$ & $4.40 \mathrm{E}-04$ \\
\hline 2.00E-05 & 4.00E-05 & $4.20 \mathrm{E}-04$ \\
\hline 2.00E-05 & $>1.00 \mathrm{E}-06$ & $5.00 \mathrm{E}-04$ \\
\hline 2.00E-05 & 4.00E-05 & $3.80 \mathrm{E}-04$ \\
\hline$>1.00 \mathrm{E}-06$ & 2.00E-05 & $3.00 \mathrm{E}-04$ \\
\hline $2.00 \mathrm{E}-05$ & $8.00 E-05$ & $2.00 \mathrm{E}-04$ \\
\hline
\end{tabular}


Table 6 (IAC 2) Frequencies of violation of $Y R A$ for Hare, Iterative Borda and Coombs, with $n=75$ and $n=100$.

\begin{tabular}{|c|c|c|c|}
\hline & \multicolumn{3}{|c|}{$n=75$} \\
\hline$t$ & HP & IBP & CP \\
\hline 1 & $>1.00 \mathrm{E}-06$ & $>1.00 \mathrm{E}-06$ & $>1.00 \mathrm{E}-06$ \\
\hline 2 & $>1.00 \mathrm{E}-06$ & $>1.00 E-06$ & $>1.00 \mathrm{E}-06$ \\
\hline 3 & $1.60 \mathrm{E}-04$ & $>1.00 E-06$ & $>1.00 \mathrm{E}-06$ \\
\hline 4 & $4.00 E-05$ & $>1.00 \mathrm{E}-06$ & 4.00E-05 \\
\hline 5 & 1.00E-04 & $>1.00 \mathrm{E}-06$ & $1.80 \mathrm{E}-04$ \\
\hline 6 & $2.00 E-05$ & $>1.00 \mathrm{E}-06$ & $1.40 \mathrm{E}-\mathrm{O} 4$ \\
\hline 7 & $6.00 \mathrm{E}-05$ & $>1.00 \mathrm{E}-06$ & $3.60 \mathrm{E}-04$ \\
\hline 8 & $4.00 E-05$ & $>1.00 \mathrm{E}-06$ & $2.60 \mathrm{E}-04$ \\
\hline 9 & $8.00 E-05$ & $6.00 \mathrm{E}-05$ & $4.40 \mathrm{E}-04$ \\
\hline 10 & 2.00E-05 & 6.00E-05 & $5.40 \mathrm{E}-04$ \\
\hline 15 & $6.00 \mathrm{E}-05$ & $6.00 \mathrm{E}-05$ & $7.00 \mathrm{E}-04$ \\
\hline 20 & 2.00E-05 & 2.00E-05 & $7.60 \mathrm{E}-04$ \\
\hline 25 & $8.00 E-05$ & $6.00 \mathrm{E}-05$ & $6.80 \mathrm{E}-04$ \\
\hline 30 & $1.60 \mathrm{E}-04$ & $2.00 \mathrm{E}-05$ & $3.80 \mathrm{E}-04$ \\
\hline 35 & $8.00 E-05$ & 2.00E-05 & $3.60 \mathrm{E}-04$ \\
\hline 40 & & & \\
\hline 45 & & & \\
\hline 50 & & & \\
\hline
\end{tabular}

\begin{tabular}{|c|c|c|}
\hline \multicolumn{3}{|c|}{$n=100$} \\
\hline HP & IBP & CP \\
\hline$>1.00 \mathrm{E}-06$ & $>1.00 \mathrm{E}-06$ & $>1.00 \mathrm{E}-06$ \\
\hline$>1.00 \mathrm{E}-06$ & $>1.00 \mathrm{E}-06$ & $>1.00 \mathrm{E}-06$ \\
\hline 1.OOE-04 & $>1.00 E-06$ & 2.00E-05 \\
\hline 1.00E-04 & $>1.00 \mathrm{E}-06$ & $8.00 E-05$ \\
\hline 4.00E-05 & $>1.00 \mathrm{E}-06$ & 4.0OE-05 \\
\hline$>1.00 \mathrm{E}-06$ & $>1.00 \mathrm{E}-06$ & $1.00 \mathrm{E}-04$ \\
\hline 4.00E-05 & $>1.00 \mathrm{E}-06$ & $2.80 \mathrm{E}-04$ \\
\hline 8.00E-05 & $>1.00 \mathrm{E}-06$ & $2.20 \mathrm{E}-04$ \\
\hline$>1.00 \mathrm{E}-06$ & $>1.00 \mathrm{E}-06$ & $3.60 \mathrm{E}-04$ \\
\hline$>1.00 E-06$ & 4.00E-05 & $4.80 \mathrm{E}-04$ \\
\hline 8.00E-05 & $>1.00 \mathrm{E}-06$ & $3.00 \mathrm{E}-04$ \\
\hline 4.00E-05 & $6.00 \mathrm{E}-05$ & $7.40 \mathrm{E}-04$ \\
\hline $1.60 \mathrm{E}-04$ & $1.00 \mathrm{E}-04$ & $7.80 \mathrm{E}-04$ \\
\hline 8.00E-05 & $2.00 \mathrm{E}-05$ & $5.20 \mathrm{E}-04$ \\
\hline 8.00E-05 & $6.00 E-05$ & $5.80 \mathrm{E}-04$ \\
\hline 1.60E-04 & $>1.00 \mathrm{E}-06$ & $5.60 \mathrm{E}-04$ \\
\hline 4.00E-05 & $>1.00 \mathrm{E}-06$ & $2.80 \mathrm{E}-04$ \\
\hline $8.00 \mathrm{E}-05$ & $>1.00 \mathrm{E}-06$ & $4.20 \mathrm{E}-04$ \\
\hline
\end{tabular}

Graphically these tables are illustrated as follows:

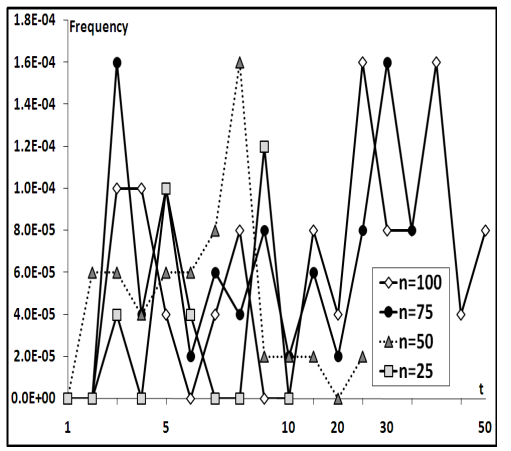

Fig. 8 Frequencies of violation of $Y R A$ under $I A C$ for Hare $(H P)$ and $n \in\{25,50,75,100\}$.

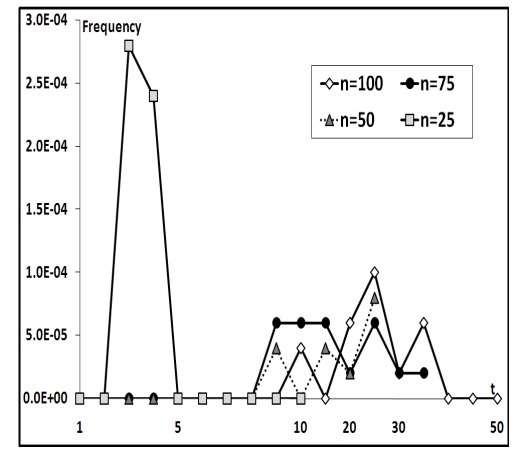

Fig. 9 Frequencies of violation of $Y R A$ under $I A C$ for Iterative Borda $(I B P)$ and $n \in\{25,50,75,100\}$. 


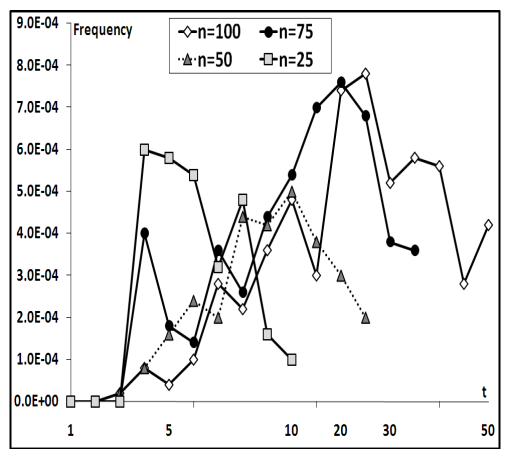

Fig. 10 Frequencies of violation of $Y R A$ under $I A C$ for Coombs $(C P)$ and $n \in\{25,50,75,100\}$.

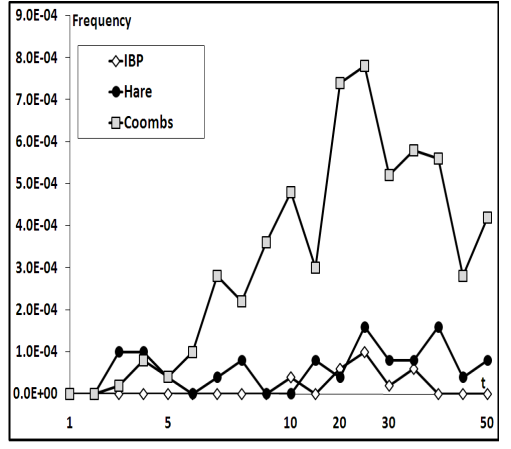

Fig. 11 A comparison of the three rules, under $I A C$, for $n=100$.

As a difference with the $I C$ hypothesis, observation of Fig. 8, 9 and 10 does not lead to a clear conclusion. However it seems that frequencies are higher as both constituencies tend to have the same size. Moreover, like Fig. 5 above, Fig. 11 shows that $C P$ is more sensitive to violations of $Y R A$ than the two other rules. However, while under $I C$ the performance of $I B P$ and $C P$ were very close, under $I A C$, there seems to be no clear difference between $I B P$ and $H P$. This shows that, to some extent, the choice of the probabilistic model can have an influence on the results: $I A C$ is known to assume some homogeneity within voters preferences, while $I C$ assumes more clearly divided views among voters. Besides, it also appears that occurrences of paradoxes are higher under $I C$ than under $I A C$ (see Gehrlein 2006, chap. 5).

We now turn, in Table 7 and in Fig. 12, to the results obtained under $I A C$ for the three special cases of bicameral congresses.

Table 7 (IAC 3) Theoretical frequencies of violation of $Y R A$

in some Western democracies under different voting rules.

\begin{tabular}{|cccc|cccc|}
$\lambda$ & Germany & France & USA & $\lambda$ & Germany & France & USA \\
0.00 & $1.00 \mathrm{E}-05$ & $2.00 \mathrm{E}-05$ & $4.00 \mathrm{E}-05$ & 0.55 & $1.00 \mathrm{E}-05$ & $2.00 \mathrm{E}-05$ & $2.00 \mathrm{E}-05$ \\
0.05 & $>1.00 \mathrm{E}-06$ & $>1.00 \mathrm{E}-06$ & $2.00 \mathrm{E}-05$ & 0.60 & $>1.00 \mathrm{E}-06$ & $2.00 \mathrm{E}-05$ & $1.00 \mathrm{E}-05$ \\
0.10 & $>1.00 \mathrm{E}-06$ & $2.00 \mathrm{E}-05$ & $3.00 \mathrm{E}-05$ & 0.65 & $>1.00 \mathrm{E}-06$ & $2.00 \mathrm{E}-05$ & $2.00 \mathrm{E}-05$ \\
0.15 & $2.00 \mathrm{E}-05$ & $>1.00 \mathrm{E}-06$ & $2.00 \mathrm{E}-05$ & 0.70 & $2.00 \mathrm{E}-05$ & $2.00 \mathrm{E}-05$ & $2.00 \mathrm{E}-05$ \\
0.20 & $1.00 \mathrm{E}-05$ & $3.00 \mathrm{E}-05$ & $1.00 \mathrm{E}-05$ & 0.75 & $1.00 \mathrm{E}-05$ & $7.00 \mathrm{E}-05$ & $2.00 \mathrm{E}-05$ \\
0.25 & $>1.00 \mathrm{E}-06$ & $2.00 \mathrm{E}-05$ & $1.00 \mathrm{E}-05$ & 0.80 & $1.00 \mathrm{E}-05$ & $1.20 \mathrm{E}-04$ & $4.00 \mathrm{E}-05$ \\
0.30 & $>1.00 \mathrm{E}-06$ & $1.00 \mathrm{E}-05$ & $>1.00 \mathrm{E}-06$ & 0.85 & $4.00 \mathrm{E}-05$ & $8.00 \mathrm{E}-05$ & $2.00 \mathrm{E}-05$ \\
0.35 & $>1.00 \mathrm{E}-06$ & $1.00 \mathrm{E}-05$ & $1.00 \mathrm{E}-05$ & 0.90 & $2.00 \mathrm{E}-05$ & $8.00 \mathrm{E}-05$ & $1.10 \mathrm{E}-04$ \\
0.40 & $1.00 \mathrm{E}-05$ & $2.00 \mathrm{E}-05$ & $1.00 \mathrm{E}-05$ & 0.95 & $1.00 \mathrm{E}-05$ & $1.00 \mathrm{E}-04$ & $1.00 \mathrm{E}-04$ \\
0.45 & $>1.00 \mathrm{E}-06$ & $1.00 \mathrm{E}-05$ & $>1.00 \mathrm{E}-06$ & 1.00 & $3.00 \mathrm{E}-05$ & $2.30 \mathrm{E}-04$ & $3.00 \mathrm{E}-05$ \\
0.50 & $>1.00 \mathrm{E}-06$ & $3.00 \mathrm{E}-05$ & $>1.00 \mathrm{E}-06$ & & & & \\
\hline
\end{tabular}




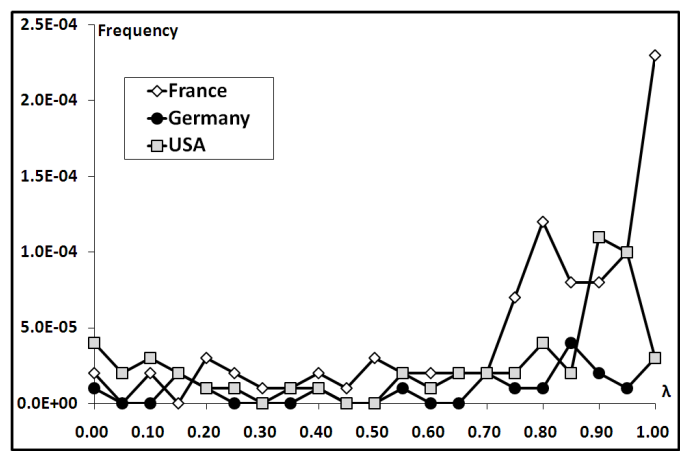

Fig.12 Comparison of the three Congresses under $I A C$ and under different voting rules $(0 \leq \lambda \leq 1)$.

Once again, Coombs procedure is more sensitive to the violation of $Y R A$ than Borda and Hare procedures; but, it is not clear from our results in Table 7 that one of these last two rules - Borda or Hare - would minimize the probability of violation of $Y R A$. More importantly, the paradox is clearly unlikely to appear in the Parliaments under study.

Now, suppose the size of any one of the two constituencies is equal to $\alpha n$, where $\alpha$ is a proportion of the total number of voters, provided that $\alpha n$ is an integer. Thus, a value of $\alpha$ equal to 0.1 means that the number of individuals in the given constituency represents $10 \%$ of the total number of individuals in $N$, which implies that the $90 \%$ other individuals are members of the other constituency. Here, we focus on large electorates - and indeed on infinite electorates - and then we assume that $\alpha$ can take any value in the interval $\left.] 0, \frac{1}{2}\right]$. Further, as a difference with computer simulations from which the results provided above have been obtained, we here provide exact values of frequencies of violation of $Y R A$. These results are obtained by use of the technique of Fishburn and Gehrlein (1976).

Let $F(\lambda, \alpha, n)$ be the likelihood that an $S P R F$ with the vector score $V^{A}=\{(1, \lambda, 0),(1,0)\}$ violates $Y R A$, for $n$ voters. We provide closed-form formulae giving this likelihood when $n=\infty$ and $\lambda \in\{0,1\}$. We have not been able to obtain results for $\lambda=\frac{1}{2}$. We then can state the following results:

Proposition 6 Let $\mathrm{HP}$ be the voting rule. Then $F(0, \alpha, \infty)=$ 


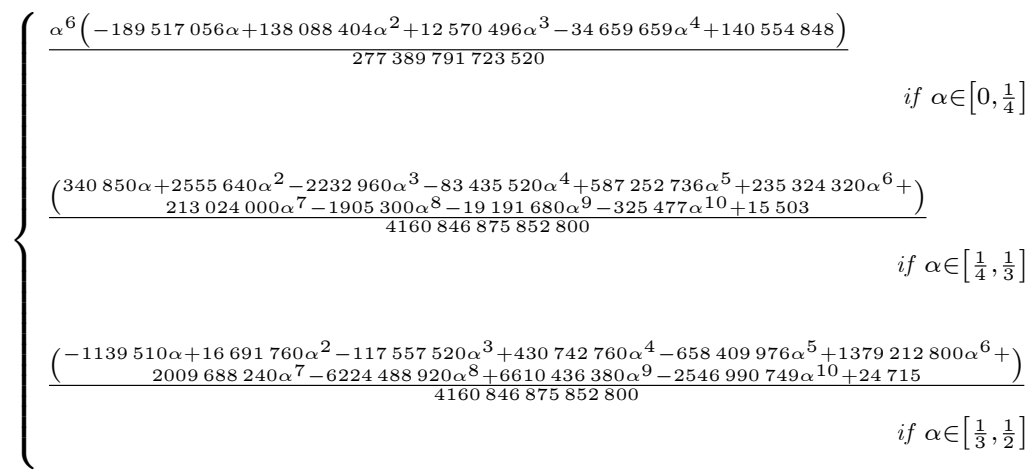

Proposition 7 Let $\mathrm{CP}$ be the voting rule. Then $F(1, \alpha, \infty)=$ $\begin{cases}\frac{\alpha^{6}\left(-189517056 \alpha+138088404 \alpha^{2}+12570496 \alpha^{3}-34659659 \alpha^{4}+140554848\right)}{277389791723520} & \text { if } \alpha \in\left[0, \frac{1}{3}\right] \\ \frac{\left(\begin{array}{l}694840-23006250 \alpha+314101800 \alpha^{2}-2374579800 \alpha^{3}+11071468800 \alpha^{4}-33160212540 \alpha^{5}+ \\ 158559912000 \alpha^{6}-114436013400 \alpha^{7}+13807845900 \alpha^{8}+22578700950 \alpha^{9}-8375899073 \alpha^{10}\end{array}\right)}{81266540544000000} & \text { if } \alpha \in\left[\frac{1}{3}, \frac{1}{2}\right]\end{cases}$

For some values of $\alpha$, we have the following results in Table 8:

Table 8 (IAC 4) Violations of $Y R A$ for Hare and Coombs with large electorates and $0 \leq \lambda \leq 1$.

\begin{tabular}{|ccc|ccc|}
\hline$\alpha$ & Coombs & Hare & $\alpha$ & Coombs & Hare \\
0.025 & $5.63 \mathrm{E}-16$ & $2.39 \mathrm{E}-16$ \\
0.05 & $3.57 \mathrm{E}-14$ & $1.48 \mathrm{E}-14$ & 0.275 & $8.74 \mathrm{E}-10$ & $3.09 \mathrm{E}-10$ \\
0.075 & $4.01 \mathrm{E}-13$ & $1.63 \mathrm{E}-13$ & 0.3 & $1.45 \mathrm{E}-09$ & $5.06 \mathrm{E}-10$ \\
0.1 & $2.23 \mathrm{E}-12$ & $8.87 \mathrm{E}-13$ & $2.31 \mathrm{E}-09$ & $7.95 \mathrm{E}-10$ \\
0.125 & $8.40 \mathrm{E}-12$ & $3.27 \mathrm{E}-12$ & 0.35 & $3.54 \mathrm{E}-09$ & $1.21 \mathrm{E}-09$ \\
0.15 & $2.47 \mathrm{E}-11$ & $9.47 \mathrm{E}-12$ & 0.375 & $5.26 \mathrm{E}-09$ & $1.78 \mathrm{E}-09$ \\
0.175 & $6.15 \mathrm{E}-11$ & $2.31 \mathrm{E}-11$ & 0.425 & $7.62 \mathrm{E}-09$ & $2.56 \mathrm{E}-09$ \\
0.2 & $1.35 \mathrm{E}-10$ & $4.99 \mathrm{E}-11$ & $0.08 \mathrm{E}-08$ & $3.60 \mathrm{E}-09$ \\
0.225 & $2.70 \mathrm{E}-10$ & $9.82 \mathrm{E}-11$ & 0.45 & $1.49 \mathrm{E}-08$ & $4.97 \mathrm{E}-09$ \\
0.25 & $5.01 \mathrm{E}-10$ & $1.79 \mathrm{E}-10$ & 0.5 & $2.03 \mathrm{E}-08$ & $6.73 \mathrm{E}-09$ \\
0.5 & $2.71 \mathrm{E}-08$ & $8.98 \mathrm{E}-09$ \\
\hline
\end{tabular}

Graphically, in Fig. 13 we have: 


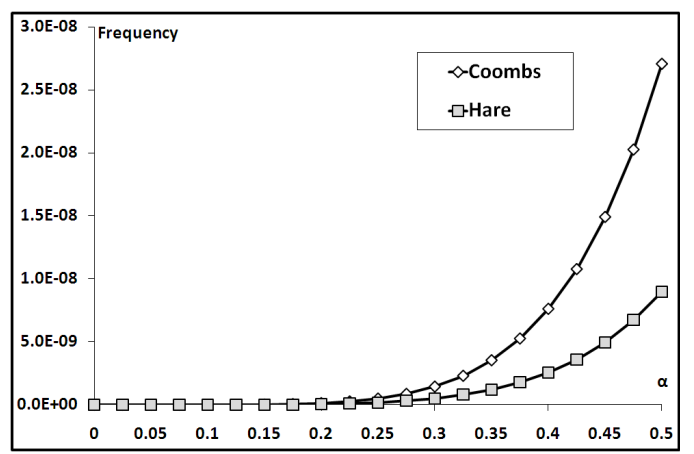

Fig. 13 Frequencies of violation of $Y R A$ under $I A C$ for

Hare and Coombs with large electorates and $0 \leq \lambda \leq 1$.

As seen above, it appears that: (i) in general, cases of violations are rather rare, (ii) frequencies get smaller as the electorate gets larger, (iii) greatest frequencies are reached for electorates with constituencies with equal size, and finally (iv) Coombs procedure is more sensitive to the violation of $Y R A$ than Hare's procedure.

\section{Concluding discussion}

This paper was devoted to the study of the sensitivity of sequential positional rules to Young's reinforcement axiom. We obtain two types of results. First, we give precision about the configurations of preferences and the number of voters at which violations of the axiom occur, and second, we provide frequencies of these occurrences. Most of these latter results are based on computer simulations - under two probabilistic classical hypotheses - but some other are obtained with the analytical Fishburn-Gehrlein technique. Illustrations are given for the special cases of Hare's Procedure, Coombs Procedure and Iterative Borda Procedure, and also for three actual Parliaments (France, Germany and the United States).

Our results show that: (i) in general, cases of violations of $Y R A$ are rather rare, (ii) although all frequencies are small, they are smaller for $H P$ and $I B P$ than $C P$, and (iii) frequencies decrease for electorates with constituencies with clearly uneven sizes.

Besides, although all these rules violate $Y R A$, the frequencies of violation are very rare. Then, since the violation of this axiom is not so frequent, one should not be unduly worried about its theoretical possibility.

However, we can make some advice in order to avoid this paradox with three alternatives. First, for small constituencies, indifferently take $H P$, or $C P$, or $I B P$, among all sequential positional rules. And second for large electorates, use $I B P$ rather than $H P$ or $C P$. 
It must also be noted that in the special case where the winner in the first constituency is the most preferred alternative of all voters in the second constituency, the violation of Young's reinforcement axiom coincides with the no-show paradox (see for example Lepelley and Merlin 2001). However, our results noticeably differ from those of Lepelley and Merlin, mainly because, as underlined above, our simulations are based on an assumption of independence between the two constituencies, which is not the case in their study.

Finally, it is worth noting that it may be interesting to consider some different contexts: more than three alternatives, more general procedures containing all $S P R$ s (for example by possibly eliminating more than one alternative at each step), or Condorcet consistent procedures.

Acknowledgements. We are grateful to two anonymous referees for very valuable comments and suggestions.

\section{References}

Fishburn, PC., Gehrlein, W.V. (1976). Condorcet's paradox and anonymous preference profiles. Public Choice, 26:1-18

Gehrlein WV (2006) Condorcet's paradox. Springer-Verlag, New York

Kelly, Jerry S (1993) Almost all social choice rules are highly manipulable, but a few aren't. Soc Choice Wel 2:161-175

Lepelley D (1996) Constant Scoring rules, Condorcet criteria and single-peaked preferences. Econ Theory 7:491-500

Lepelley D, Merlin V (2001) Scoring run-off paradoxes for variable electorates. Econ Theory 17:53-81

Mbih B, Moyouwou I, Zhao X (2006) On the responsiveness of parliamentary social choice functions. Working Paper, CREM-Université de Caen

Moulin H (1988) Axioms of cooperative decision making. Cambridge University Press, Cambridge

Nitzan S (1985) The vulnerability of point voting schemes to preference variation and strategic manipulation. Public Choice 47:349-370

Nurmi H (2005) A responsive voting system. Econ Gov 6:63-74

Reggenwetter M, Grofman B, Marley AAJ and Tselin IM (2006) Behavioral social choice. Cambridge University Press, Cambridge

Smith JH (1973) Aggregation of Preferences with Variable Electorate. Econometrica 41:1027-1041

Young HP (1974) An Axiomatization of Borda's Rule. J Econ Theory 9:43-52

Young HP (1975) Social Choice Scoring Functions. SIAM J Appli Math 28:824838Introduction 